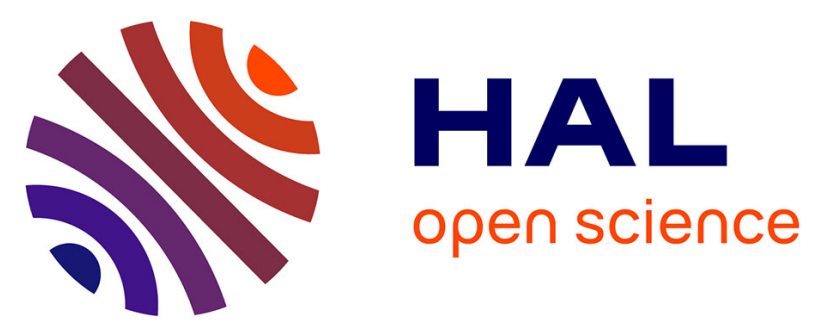

\title{
Kinetic Rotating Droplet Electrochemistry: a Simple and Versatile Method for Reaction Progress Kinetic Analysis in Microliter Volumes
}

Lylian Challier, Rebeca Miranda-Castro, Damien Marchal, Vincent Noël, François Mavré, Benoît Limoges

\section{To cite this version:}

Lylian Challier, Rebeca Miranda-Castro, Damien Marchal, Vincent Noël, François Mavré, et al.. Kinetic Rotating Droplet Electrochemistry: a Simple and Versatile Method for Reaction Progress Kinetic Analysis in Microliter Volumes. Journal of the American Chemical Society, 2013, 135 (38), pp.14215-14228. 10.1021/ja405415q . hal-03271713

\section{HAL Id: hal-03271713 \\ https://hal.science/hal-03271713}

Submitted on 27 Jun 2021

HAL is a multi-disciplinary open access archive for the deposit and dissemination of scientific research documents, whether they are published or not. The documents may come from teaching and research institutions in France or abroad, or from public or private research centers.
L'archive ouverte pluridisciplinaire HAL, est destinée au dépôt et à la diffusion de documents scientifiques de niveau recherche, publiés ou non, émanant des établissements d'enseignement et de recherche français ou étrangers, des laboratoires publics ou privés. 


\title{
Kinetic Rotating Droplet Electrochemistry: a Simple and Versatile Method for Reaction Progress Kinetic Analysis in Microliter Volumes.
}

\author{
Lylian Challier, ${ }^{\mathrm{a} \ddagger}$ Rebeca Miranda-Castro, ${ }^{\mathrm{a}, \mathrm{b}}{ }^{\ddagger}$ Damien Marchal, ${ }^{\mathrm{b}}$ Vincent Noël, ${ }^{\mathrm{a}}$ François Mavré, ${ }^{\mathrm{b}, *}$ \\ Benoît Limoges ${ }^{b, *}$
}

${ }^{a}$ ITODYS, UMR 7086 CNRS, and ${ }^{b}$ Laboratoire d'Electrochimie Moléculaire, UMR 7591 CNRS, Univ Paris Diderot, Sorbonne Paris Cité, 15 rue Jean-Antoine de Baïf, F-75205 Paris Cedex 13, France.

\begin{abstract}
Here, we demonstrate a new generic, affordable, simple, versatile, sensitive and easy-to-implement electrochemical kinetic method for monitoring, in real time, the progress of a chemical or biological reaction in a microdrop of a few tens of microliters, with a kinetic time resolution of ca. $1 \mathrm{~s}$. The methodology is based on a fast injection/mixing of a reactant solution $(1-10 \mu \mathrm{L})$ in a reaction droplet (15-50 $\mu \mathrm{L})$ rapidly rotated over the surface of a non-moving working electrode, and on the recording of the ensuing transient faradaic current associated to the transformation of one of the components. Rapid rotation of the droplet was ensured mechanically by a rotating rod brought in contact atop the droplet. This simple set-up makes it possible to mix reactants efficiently and rotate the droplet at a high spin rate, hence generating a well-defined hydrodynamic steady-state convection layer at the underlying stationary electrode. The features afforded by this new kinetic method were investigated for three different reaction schemes: (i) the chemical oxidative deprotection of a boronic ester by $\mathrm{H}_{2} \mathrm{O}_{2}$, (ii) a biomolecular binding recognition between a small target and an aptamer, and (iii) the inhibition of the redox-mediated catalytic cycle of horseradish peroxidase (HRP) by its substrate $\mathrm{H}_{2} \mathrm{O}_{2}$. For the small target/aptamer binding reaction, the kinetic and thermodynamic parameters were recovered from rational analysis of the kinetic plots, whereas for the HRP catalysis/inhibition the experimental amperometric kinetic plots were reproduced from numerical simulations. From the best fits of simulations to the experimental data, the kinetics rate constants primarily associated to the inactivation/reactivation pathways of the enzyme were retrieved. The ability to perform kinetics in microliter-size samples makes this methodology particularly attractive for reactions involving low-abundant and/or expensive reagents.
\end{abstract}

\section{INTRODUCTION}

Monitoring the progress of a chemical or biochemical reaction (e.g., by following the reactant conversion or product formation over time) with an appropriate kinetic technique is essential to determine the rate laws of reactions and to aid in elucidation of reaction mechanisms. ${ }^{1,2,3,4}$ This may be accomplished by a wide range of kinetic methods, the most common of which take advantage of changes in optical signals, such as UV-visible absorbance or fluorescence, which often accompany a reaction. ${ }^{5}$ For monitoring fast reactions on timescales ranging from milliseconds to several tens of seconds, rapid mixing techniques are required (e.g., stopped-flow, quenched flow or continuous flow). In these ones, two or more reactant solutions are rapidly mixed in a chamber and the ensuing reaction solution is monitored by an appropriate real-time detection method. A major strength of rapid mixing methods is that they can be readily combined with a wide range of detection methods and, though optical techniques have been predominantly implemented, ${ }^{3,5}$ non-optical detections such as $\mathrm{NMR},{ }^{6,7}$ isothermal titration calorimetry, ${ }^{8}$ or small-angle X-ray scattering ${ }^{9}$ have been proven useful alternatives.

Surprisingly, despite the many practical advantages of electrochemical detection methods including high temporal resolution, sensitivity, low cost, and simplicity, only a scarce num- ber of kinetic methods combining rapid mixing of reactants with an electrochemical readout have been so far reported. One example, recently described, ${ }^{10}$ is based on a segmented flow microfluidic platform in which microdroplets generated from the mixing of two reagents at a $\mathrm{T}$-junction are moved through a microchannel and, at some positions downstream, the electroactive content of the microdroplets is amperometrically detected by wire electrodes inserted into the microchannel. The method was illustrated with the kinetic analysis of the enzymatic decomposition of $\mathrm{H}_{2} \mathrm{O}_{2}$ by catalase. This technique has the advantage of using low sample volumes (a few tens of microliters), with the possibility to reach a time resolution down to $50 \mathrm{~ms}$. However, the principle is inherently limited by a low sampling rate because of the restricted number of electrodes that could be inserted into the microfluidic channel, leading thus to rather poorly defined kinetic plots. The other examples are all based on the use of a rotating disk electrode (RDE), generally mounted in a standard closed electrochemical cell containing a few milliliters of solution. ${ }^{11,12,13,14,15}$ The RDE ensures rapid mixing of the reactant injected into the cell (sometimes this is accompanied by magnetic stirring or bubbling with an inert gas ${ }^{12}$ ), as well as fast and controlled mass transport of the reactant to the electrode surface. Under these conditions, a mixing time shorter than $0.5 \mathrm{~s}$ has been reported. ${ }^{12}$ The technique was successfully applied to the electrochemical characterization of homogene- 
ous $^{11}$ and heterogeneous ${ }^{12,14}$ kinetics of enzyme reactions, as well as to quantitative analysis of the heterogeneous binding kinetics of a ligand in solution to a receptor immobilized on the RDE. ${ }^{13,15}$ It is interesting to note that these hydrodynamic electrochemical kinetic methods can be sub-divided in two categories: those in which the fluid is in motion with respect to a static electrode, and those in which this is the electrode itself that is moving relative to the solution. Whatever the strategy, each provided a convective regime (or more rigorously a chaotic advection in the case of microdroplets flowing through a winding microchannel ${ }^{10}$ ) that has the purpose to rapidly mix the reactants of the sample solution and at the same time to promote fast diffusion rate of species to the sensing electrode surface. From the efficiency of these processes thus depends the capacity to determine rapid reaction rates and the ability to sensitively and accurately detect the consumption or production of one of the participants.

The $\mathrm{RDE}^{16,17}$ remains the workhorse of hydrodynamic electrochemical methods (even though a wide range of alternative hydrodynamic approaches have been developed during the last 20 years $\left.{ }^{18,19,20,21,22}\right)$. It exhibits a number of advantages such as a high degree of control of the diffusion flux through a fine tune of the electrode rotation rate, allowing thus to record a steady-state current with high precision and reproducibility. However, it has also a number of drawbacks. For conventional RDE, only macro-samples of solution are accessible (typically a few milliliters), consequently prohibiting reaction kinetic studies of low-abundant and expensive reagents (e.g., biomolecules). Moreover, the electrical noise, which determines the ability to reach low detection limits, is attendant to the electrical contacts between rapidly moving and non-moving parts in the electrode. Additionally, the screening of RDE made of different conductive materials, different surface modifications, and various shapes and/or geometries is in practice not simple to achieve (note that this is for this reason that the hangingmeniscus rotating disk technique has been expressly developed and applied to hydrodynamic electrochemistry at metal single crystals ${ }^{23,24}$ ). The implementation of an equivalent of RDE for performing hydrodynamic electrochemistry in microliter samples and in a configuration that would facilitate the screening of different electrode designs and materials is therefore of great interest. In that vein, Gratzl and coll. have described a system that addresses these issues. ${ }^{25,26}$ The system consists of applying a small sample droplet $(20 \mu \mathrm{L})$ over a gold ring working electrode and then, by using a mild gas jet directed tangentially to the droplet of solution, forcing it to rotate, thereby generating a steady-state current. This rotating sample strategy was shown to be as effective as a rotating electrode system. The approach however suffers from rather fast evaporation of the sample, complicating thus the current response analysis as a function of time. Introduction of a RDE directly over the top of an aqueous microdrop is an alternative route to perform hydrodynamic electrochemistry in small sample volumes. ${ }^{27}$ It was advantageously applied to magnetic microbead-based enzyme immunoassays. ${ }^{28,29}$ However, apart from the possibility of working in small volumes, the approach shows the same limitations than at conventional RDE.

In the present work, a new affordable, simple, versatile, robust, and easy-to-implement electrochemical kinetic method has been developed for monitoring, in real time, the progress of a chemical or biological reaction in a few tens of microliters with a kinetic time resolution of ca. $1 \mathrm{~s}$. The principle basically consists to rapidly inject and mix a reactant solution (1-10 $\mu \mathrm{L})$ in a small drop of a reaction solution $(15-50 \mu \mathrm{L})$ that is rapidly spinning over the surface of a non-moving working electrode polarized at an appropriate potential. The ensuing transient faradaic current associated to the consumption or production of one of the components in the microdrop reactor is subsequently recorded. Rapid rotation of the droplet was ensured mechanically by a rotating rod (in fact a standard $\mathrm{RDE}$ that was here just used as a mechanical rotator) brought in contact atop the droplet. As it will be shown, this simple set-up makes it possible to efficiently mix and rotate the sandwiched droplet at high spin rate and hence to generate a well-controlled hydrodynamic steady-state convection layer at the underlying stationary working electrode. This new configuration also eliminates all problems related to the moving electrical contact in RDE and provides a high degree of freedom in the choice and design of the working electrode. In the present work, disposable screen-printed electrodes have been used, which is very convenient for reproducing a large number of experiments with fresh electrode surfaces without need of surface polishing. These electrodes also possess a remarkably low capacitance which is advantageous for detecting low concentrations. ${ }^{30}$ Moreover, because of the highly favorable hydrodynamic conditions and short response time of the amperometric measurement, it makes it possible to electrochemically monitor reaction progress continuously, from zerotime, with a high sampling rate (up to $1 \mathrm{MHz}$ with standard commercialized potentiostats).

To evaluate the hydrodynamic properties of the rotating droplet system, we have first examined the effect of the rod spin rate on the electrochemical response, as well as the influence of several geometric parameters such as the gap height separating the rotating rod from the underlying stationary working electrode, the volume of the rotated droplet, and the working electrode area-to-droplet volume ratio. The mixing time required to homogenously disperse the injected reactant was also carefully assessed. Thereafter, the relevance and features of the electrochemical method for reaction progress kinetic analysis in low-volume samples were investigated for three different illustrating reaction schemes: (i) an irreversible bimolecular chemical reaction based on the oxidative deprotection of an aryl boronic ester by hydrogen peroxide, ${ }^{31}$ (ii) a reversible biomolecular binding reaction through the enantiospecific molecular recognition of the small target Ltyrosinamide by its 49 -mer aptamer, ${ }^{32}$ and (iii) a more complex reaction with the reversible inhibition of the catalytic cycle of horseradish peroxidase (HRP) by its substrate hydrogen peroxide. ${ }^{33,34}$

\section{MATERIALS AND METHODS}

Reagents. $\mathrm{MgCl}_{2}$ • $6 \mathrm{H}_{2} \mathrm{O}$ (Sigma), L-tyrosinamide (Aldrich), $\mathrm{LiClO}_{4}$ (Aldrich), hydrogen peroxide (30\% wt. reagent grade; Prolabo), bovine serum albumin (BSA; Sigma), $p$ aminophenol (Prolabo), $p$-aminophenyl boronic acid pinacol ester (Tokyo Chemical Industry) and ferrocene methanol (Aldrich) were used without further purification. The $\left[\mathrm{Os}^{\mathrm{II}}(\mathrm{bpy})_{2} \mathrm{pyCl} \mathrm{PF}_{6}\right.$ and $\left[\mathrm{Os}^{\mathrm{II}}(\mathrm{bpy})_{3}\right]\left(\mathrm{PF}_{6}\right)_{2}$ were synthesized according to a published procedure. ${ }^{35}$ Lyophilized HRP was purchased from Sigma (type VI-A, RZ = 3.5) and used without further purification. The concentration of HRP was spectrophotometrically determined at $403 \mathrm{~nm}$ using a Soret extinction coefficient of $102 \mathrm{mM}^{-1} \mathrm{~cm}^{-1}$. The enzyme reaction buffer (EB, pH 7.4) was prepared from $4.3 \mathrm{mM} \mathrm{NaH} \mathrm{PO}_{4}$, $15.1 \mathrm{mM} \mathrm{Na} \mathrm{HPO}_{4}, 50 \mathrm{mM} \mathrm{NaCl}$ and $1 \mathrm{mg} / \mathrm{mL}$ BSA. Adding 
BSA to the enzyme buffer allows minimizing the loss and/or denaturation of the enzyme at the air/liquid or solid/liquid interfaces. The Tris buffer (TB, $\mathrm{pH}$ 7.4) used for the aptamer binding experiments was made of $5 \mathrm{mM}$ Tris buffer, $10 \mathrm{mM}$ $\mathrm{MgCl}_{2}$ and $50 \mathrm{mM} \mathrm{NaCl}$.

The oligonucleotides were synthesized and HPLC-purified by Eurogentec (Angers, France) and their concentration was controlled by UV-visible spectroscopy using a Nanodrop 2000 spectrophotometer (ThermoFisher). The aptamer oligonucleotide sequence was (from 5 ' to 3 '): ${ }^{36}$

\section{Apt $_{49}$ : AATTCGCTAGCTGGAGCTTGGATTGATGTGGTG} TGTGAGTGCGGTGCCC

Milli-Q water (18.2 M $\Omega \mathrm{cm}$, TKA MicroPure UV) was used to prepare all aqueous solutions.

Instrumentation and electrodes. Electrochemical measurements were carried out with a computer-controlled AutoLab PGSTAT 12 potentiostat interfaced to a GPES 4.9 software (EcoChemie B.V. Utrecht, The Netherlands).

Thick-film screen printing was used to shape the reaction well and the three-electrode cell according to the final design shown in Figure 1A. A DEK model-65 semiautomatic screenprinter (Presco, USA) was used to deposit the successive thick film layers on planar polyethylene terephthalate films through stainless-steel wire mesh screens. The working and counter carbon-based screen-printed electrodes were prepared from the carbon ink Electrodag PF-407A (Acheson Colloids Co), whereas the silver-based pseudo-reference electrode was obtained from the silver ink Electrodag $418 \mathrm{~S}$ (Acheson Colloids Co). A primary silver layer was deposited onto the polyethylene terephthalate surface to form the electrical contacts and the internal reference electrode pattern using a 230 mesh-count per in. screen. The silver layer was cured for $15 \mathrm{~min}$ in an oven at a temperature of $120^{\circ} \mathrm{C}$. The carbon layer was next deposited to form the working and counter electrode patterns using a 230 mesh-count per in. screen. After the ink leveled for a few minutes at room temperature, the layer was dried in an oven at $120^{\circ} \mathrm{C}$ for $15 \mathrm{~min}$. Finally, a last layer of a thick film curable dielectric (Vinilfast 36, Kiian, Italy) was printed through a 230 mesh screen to form the reaction well (circular well of 5-mm diameter) and to insulate the conductive paths of the electrodes. The insulating layer was cured in an oven at $120^{\circ} \mathrm{C}$ for $15 \mathrm{~min}$. The layer thicknesses were determined with a profilometer (model Alpha-Step 500, KLA-Tencor, USA) (Figures S1). The thickness of the silver and the carbon layers were $10 \pm 0.5$ and $6 \pm 0.5 \mu \mathrm{m}$, and the insulating layer thickness was $15 \pm 0.5 \mu \mathrm{m}$. The diameter of the sensing area of the working carbon electrode was $1.5 \mathrm{~mm}$ (i.e., $S=0.0177 \mathrm{~cm}^{2}$ ) but a few experiments were also performed with a larger diameter of $3 \mathrm{~mm}$ (i.e., $S=0.071 \mathrm{~cm}^{2}$ ).

Unless otherwise stated, all potentials indicated in the text are expressed versus the silver-based screen printed pseudoreference electrode (i.e., $E_{\text {Ref }} \sim+0.3 \mathrm{~V} v$ s. SHE).

Experimental set-up. The experimental set-up is schematically depicted in Figure 1. The planar three-electrode electrochemical microcell fabricated by screen printing is affixed flat over a multi-axis translational mechanical stage (Sutter Instrument Company). The droplet of the reaction solution (15$50 \mu \mathrm{L})$ is simply deposited over the three-electrode microcell and then maintained in place by the hydrophobic screenprinted insulating layer which defines a sort of circular microwell (5-mm diameter) centered on the screen-printed carbon working electrode. Proper choice of the inner diameter of the hydrophobic layer ensured a hemispherical-shaped drop. With the help of the multi-axis translational mechanical stage, the deposited droplet was brought in contact perpendicular to the rotating rod and centered to the axial axis of the shaft; thereby forming a sandwiched sand clock-shaped droplet between the screen-printed working electrode and the base of
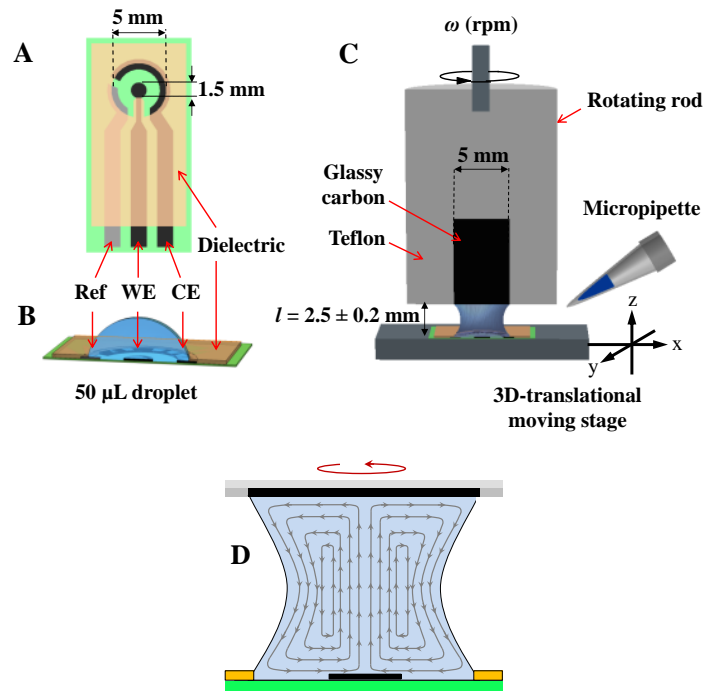

Figure 1. (A) Graphic representation (1:1 drawing scale) of the screen-printed three-electrode electrochemical microcell. WE: carbon working electrode. Ref: silver reference electrode. CE: carbon counter-electrode. (B) Cross-sectional view of a $50 \mu \mathrm{L}$ droplet deposited over the electrochemical microcell delimited by the circular dielectric layer (2:1 drawing scale). (C) Crosssectional view of the rotating droplet system (1:1 drawing scale). On the right is shown the micropipette ready for the injection of a reactant solution. (D) Schematic representation of the streamlines of recirculating flow inside the rotated droplet (cross-sectional view of the sandwiched droplet).

the rotating rod (unless otherwise stated, the distance between the extremity of the rod and the screen-printed electrodes was set to $2.5 \mathrm{~mm}$ ). The rotating rod was a standard glassy carbon RDE tip (made of a carbon disk electrode of 5-mm diameter embedded in an inert and insulating Teflon cylinder) mounted on a shaft attached to an adjustable speed rotator AFMSRX (Pine Research Instrumentation, USA). Since the glassy carbon RDE is not used during the experiments, it was disconnected from the shaft to avoid any leakage current. According to the relatively high surface tension and strong capillary forces exerted at the scale of the aqueous drop, transmission of the mechanical rotating movement from the cylindrical tip to the droplet sample was possible. As it will be shown, this simple set-up permits to rotate the droplet at a spin rate up to $3500 \mathrm{rpm}$, with a high degree of control and reproducibility.

Before experiments, the surface of the glassy carbon disk embedded in the rod as well as the overall screen-printed carbon electrodes were passively coated with a layer of BSA by spreading a droplet of $1 \mathrm{mg} / \mathrm{mL}$ solution over the electrodes for $15 \mathrm{~min}$ at room temperature. The BSA coating offers the advantage to increase the wettability of the two opposite surfaces in contact with the droplet and also to reduce the nonspecific adsorption of molecules on these surfaces, and this without significantly hindering the accessibility and heterogeneous electron transfer properties of small redox molecules to the underlying working electrode surface. The marked contrast between the hydrophilic BSA-coated interfaces and the surrounding hydrophobic materials (i.e., Teflon cylinder of the 
rod and insulating dielectric layer of the microcell), at both sides of the sandwiched droplet, helps to maintain a good drop adhesion to the rotating rod and circular microcell. After BSA coating, the screen-printed working electrodes were systematically cycled in a $0.1 \mathrm{M}$ phosphate buffer (between $0.0 \mathrm{~V}$ and $0.8 \mathrm{~V}$ at $v=0.05 \mathrm{~V} \mathrm{~s}^{-1}$ ) until the capacitive background current was stabilized. The entire rotating droplet experiments were done at room temperature $\left(\sim 20^{\circ} \mathrm{C}\right)$.

Gold-plated screen-printed electrodes were produced by electrodeposition of gold at $-0.5 \mathrm{~V}(v s$. SCE) for $240 \mathrm{~s}$ in a 0.1 $\mathrm{M} \mathrm{HCl}$ solution containing $4 \mathrm{~g} \mathrm{~L}^{-1} \mathrm{HAuCl}_{4}$.

The spectroscopic kinetics determination of the oxidative deprotection of the $p$-aminophenyl boronic acid pinacol ester by hydrogen peroxide was performed with a UV-visible AnalytikJena Specord S600 spectrophotometer. The temperature of the standard quartz cell (1-cm path length) was maintained at $20{ }^{\circ} \mathrm{C}$. The time-course absorbance change resulting from the conversion of the boronic ester $(0.1 \mathrm{mM}$ in $0.1 \mathrm{M}$ phosphate buffer, $\mathrm{pH} 7.4$ ) into $p$-aminophenol was monitored at $292 \mathrm{~nm}$ for different concentration of $\mathrm{H}_{2} \mathrm{O}_{2}$ (ranging from 1 to $5 \mathrm{mM}$ ). From the slope of the dependence of the initial rate of absorbance change as a function of $\mathrm{H}_{2} \mathrm{O}_{2}$ concentration, a second order rate constant of $k=4.1 \pm 0.2 \mathrm{M}^{-1} \mathrm{~s}^{-1}$ was obtained.

Numerical simulations. Simulations of the homogeneous aptamer binding kinetics by numerical resolution of the rate differential equations were carried out with the Gepasi 3.30 freeware. ${ }^{37}$ Simulations of the transient amperometric catalytic currents resulting from the redox mediated catalytic reaction scheme of HRP were performed with the DigiElch 7D software from ElchSoft (Germany). ${ }^{38}$ In order to simulate a steady-state mass transport through a constant diffusion layer thickness, the chronoamperometric mode at a microdisk electrode was selected in DigiElch. The size of the microdisk electrode used for the simulation was selected in such a way to have a steady-state mass transport equivalent to the one obtained experimentally at the rotating droplet system. This was achieved from comparison of the magnitude of simulated steady-state current densities to those obtained experimentally at a given mediator concentration and rod rotation rate. A microdisk electrode of 30- $\mu \mathrm{m}$-diameter was for example used since it affords a simulated steady-state current density of 7.6 $\mu \mathrm{A} / \mathrm{cm}^{2}$ for a $20 \mu \mathrm{M}$ redox species having a diffusion coefficient of $4.5 \times 10^{-6} \mathrm{~cm}^{2} \mathrm{~s}^{-1}$, which typically corresponds to the value experimentally obtained for the $\left[\mathrm{Os}^{\mathrm{II}}(\mathrm{bpy})_{2} \mathrm{pyCl}\right]^{+}$oxidized at a 2000-rpm-rotated droplet. Once the size of the simulated microdisk electrode was selected, the overall reactions of the HRP mechanism including their associated kinetic rate constants, as well as the concentrations and diffusion coefficients of each species were input to the DigiElch program for simulating the chronoamperometric responses. Because the DigiElch software does not allow to simulate the injection of a reagent at a well-defined time, we have overcome this problem by starting (i.e. at $t=0$ ) both the experiments and simulations from the reduced form of the redox mediator. Under these conditions, the simulated and experimental currents could effectively start from a zero current value. For the simulations, the different enzyme forms were considered as practically immobile by setting the diffusion coefficient at an arbitrarily low value of $10^{-10} \mathrm{~cm}^{2} \mathrm{~s}^{-1}$, whereas the diffusion coefficient of the reduced and oxidized forms of the mediator were the same than those experimentally determined (i.e., $D_{Q}=4.5 \times 10^{-6}$ $\mathrm{cm}^{2} \mathrm{~s}^{-1}$ and $D_{P}=3.2 \times 10^{-6} \mathrm{~cm}^{2} \mathrm{~s}^{-1}$ ) and the diffusion coefficient of $\mathrm{H}_{2} \mathrm{O}_{2}$ was taken equal to $1.6 \times 10^{-5} \mathrm{~cm}^{2} \mathrm{~s}^{-1}$. 33

\section{RESULTS AND DISCUSSION}

Characterization of the hydrodynamic properties of the rotating droplet system. Under the experimental conditions schematically depicted in Figure 1, the hydrodynamic conditions settled at the droplet/working electrode interface were examined by cyclic voltammetry $(\mathrm{CV})$ at a $50 \mu \mathrm{L}$ droplet solution of ferrocene methanol $(\mathrm{FcMeOH}, 50 \mu \mathrm{M})$ deposited over a screen-printed electrochemical microcell and for different rod spin rates (ranging from 0 to $3500 \mathrm{rpm}$ ). The gap height $(l)$ separating the extremity of the rotating rod from the underlying screen-printed working electrode was set at a value of $2.5 \pm 0.2 \mathrm{~mm}$. Under these conditions, the strong capillary forces and surface tension occurring at the scale of the $50 \mu \mathrm{L}$

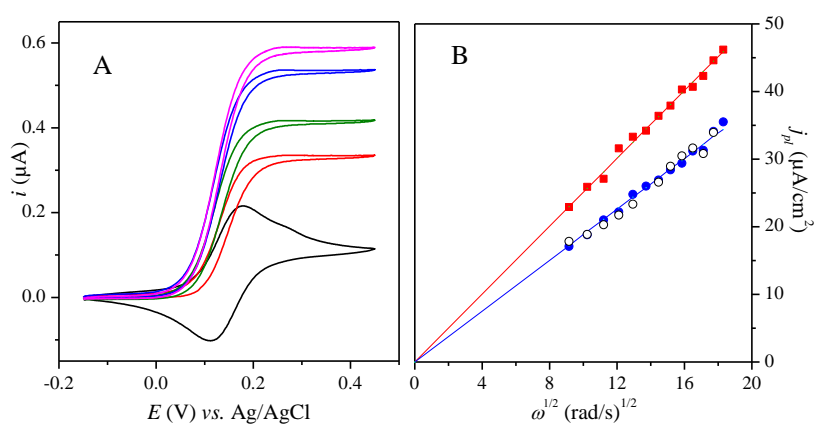

Figure 2. (A) CVs $(v=0.1 \mathrm{~V} / \mathrm{s})$ recorded at a $50 \mu \mathrm{L}$-rotated droplet $\left(50 \mu \mathrm{M} \mathrm{FcMeOH}\right.$ in $\left.0.1 \mathrm{M} \mathrm{LiClO}_{4}\right)$ sandwiched $(l=2.5 \mathrm{~mm})$ between the rotating rod and a screen-printed electrochemical microcell $\left(S=0.0177 \mathrm{~cm}^{2}\right)$ and for different rod rotation rates: (from bottom to top CV) $\omega=0,1000,1600,2400$ and $2800 \mathrm{rpm}$. (B) CV plateau current densities $(v=0.1 \mathrm{~V} / \mathrm{s})$ as a function of $\omega^{1 / 2}$ for: (red plain square) a standard working $\mathrm{RDE}$ in a $5 \mathrm{~mL}$ of 50 $\mu \mathrm{M} F \mathrm{FcMeOH}$, (black open circle) a standard working RDE on top of a $50 \mu \mathrm{L}$ droplet of $50 \mu \mathrm{M} \mathrm{FcMeOH}$, and (blue plain circle) a 50 $\mu L$-rotated droplet under the same conditions than in A. Plain lines: best linear regressions $\left[\mathrm{RDE}\right.$ : slope $=(2.51 \pm 0.01) \times 10^{-6}$ $\mathrm{A} / \mathrm{cm}^{2} /(\mathrm{rad} / \mathrm{s})^{1 / 2} ; \mathrm{r}^{2}=0.9997 ;$ rotated droplet: slope $=(1.88 \pm 0.01)$ $\times 10^{-6} \mathrm{~A} / \mathrm{cm}^{2} /(\mathrm{rad} / \mathrm{s})^{1 / 2} ; \mathrm{r}^{2}=0.9996 ; \mathrm{RDE}$ on top of the microdrop: slope $\left.=(1.87 \pm 0.01) \times 10^{-6} \mathrm{~A} / \mathrm{cm}^{2} /(\mathrm{rad} / \mathrm{s})^{1 / 2} ; \mathrm{r}^{2}=0.9991\right]$.

aqueous droplet help to maintain the solution between the upper base of the rod and the underlying surface of the microcell, up to a 3500-rpm rotation rate. The classical peak-shaped diffusion-controlled reversible wave obtained under stationary conditions in $\mathrm{CV}$ is converted into a typical sigmoid-shaped wave under mechanical motion of the rotating rod (Figure 2A). The limiting plateau current witnesses the steady-state diffusion rate of the redox species at the electrode surface through a constant diffusion boundary layer of thickness $\delta$. Besides, plateau current densities $\left(j_{p l}\right)$ were observed to vary proportionally to the concentration of $\mathrm{FcMeOH}$ (compare Figures 2A and S2) and linearly with the square root of the rod spin rate $(\omega)$ (Figure $2 \mathrm{~B}$ ), but with a slope $d j_{p l} / d \omega^{1 / 2}$ lower than at a conventional RDE in a standard electrochemical cell (i.e., in $5 \mathrm{~mL}$ of $50 \mu \mathrm{M} \mathrm{FcMeOH}$ ).

In an attempt to better understand why the hydrodynamic convection obtained at a conventional RDE does not completely transpose in our system, the glassy carbon disk embedded in the Teflon rotating rod was used momentarily as a working electrode on the top of the microdrop. ${ }^{39}$ Under these conditions, the resulting linear plot of $j_{p l}$ as a function of $\omega^{1 / 2}$ was observed to perfectly overlay the plot previously obtained with the rotated droplet configuration (Figure 2B). This result underlines the production of an identical hydrodynamic con- 
vection at the two opposite interfaces of the sandwiched droplet, thereby suggesting a high symmetry in the fluid movement induced from the spinning rod. By analogy to the recirculation flow patterns generated at a conventional RDE immersed in a cell of restricted volume (i.e., in a configuration where the walls and the bottom of the cell are close to the RDE), ${ }^{40,41}$ it can be assumed that the flow generated by the rotation of the rod on top of the droplet similarly induces a symmetrical recirculation of the liquid inside the droplet. This would mean that, as schematically depicted in Figure 1D, the rotating unit should drag the fluid by a flow normal to its surface and, because of the centrifugal force created by the rotating disk in contact to the liquid, should throw the solution outward from the center in a radial direction. Consequently when the liquid laterally displaced by the rotating rod reaches the external air/liquid walls of the droplet, it must change direction by moving downwards to the bottom working electrode. At this point, it changes direction again and moves towards the center of the droplet where it meets the flow coming from the opposite air/liquid wall, to finally moves upwards to the rotating disk, forming thus a recirculating convective flow inside the droplet. As a result, fluid motion transmits symmetrically from the moving interface up to the opposite non-moving surface. This flow pattern was clearly discerned and confirmed experimentally from a simple visual inspection of the movement of the colored liquid that was generated from the dissolution of a small crystal of potassium permanganate added to a droplet under rotation.

At a conventional RDE, expression of the steady-state plateau current, $i_{p l}$, is given by the Levich equation: ${ }^{16}$

$$
i_{p l}=\frac{n F S D C^{0}}{\delta}
$$

with at $25^{\circ} \mathrm{C}, \delta=1.61 D^{1 / 3} v^{1 / 6} \omega^{-1 / 2}$, and where $n$ is the number of electrons exchanged, $F$ the Faraday constant, $S$ the electrode surface area (in $\mathrm{cm}^{2}$ ), $D$ the diffusion coefficient of $\mathrm{FcMeOH}$ (in $\mathrm{cm}^{2} \mathrm{~s}^{-1}$ ), $C^{0}$ the bulk concentration of $\mathrm{FcMeOH}$ (in $\mathrm{mol} \mathrm{cm} \mathrm{cm}^{-3}$ ), $\delta$ the diffusion-convection layer thickness (in $\mathrm{cm}), v$ the kinematic viscosity of the solvent (in $\mathrm{cm}^{2} \mathrm{~s}^{-1}$ ) and $\omega$ the angular velocity (in $\mathrm{rad} \mathrm{s}^{-1}$ ). The fact that the current density with the rotated droplet system is systematically $25 \%$ lower than predicted by the Levich equation (Figure 2B) clearly indicates that the mass transport efficiency is decreased by $25 \%$ with respect to a conventional RDE. In order to determine if such a loss of mass transport efficiency may be influenced by the droplet volume, $V$, and gap height, $l$, the magnitude of the steady-state current at $2500 \mathrm{rpm}$ was examined for different values of $V$ and $l$ ranging from $15 \leq V \leq 50 \mu \mathrm{L}$ and $1.0 \leq l \leq 3.0 \mathrm{~mm}$. The experimental CVs (Figure S3) show that, whatever $l$ and $V$, the steady-state current remains unchanged, demonstrating that the $25 \%$ loss in mass transport efficiency is independent of $V$ and $l$ within the range of tested values. Such a behavior, although difficult to interpret without detail knowledge of the hydrodynamic flow, is nevertheless in line with the idea of a centrosymmetric circular convective flow. It also suggests that the fluid velocity (in particular the axial fluid velocity - or suction velocity - assumed to primarily control the magnitude of the steady-state current) is poorly dependent on the geometrical features of the system (within the narrow ranges here explored). The independence of the steady-state current on the distance $l$ is of practical interest because precise control of this parameter is thus not required.
This was also the case for the position of the center of the working electrode relative to the axial center of the rotating shaft, since a small offset of the working electrode from the axis of rotation was observed to do not noticeably change the magnitude of the steady-state current in CV (not shown). Finally, the experiment obtained at the lowest volume of solution demonstrates that hydrodynamic electrochemistry is achievable in only $15 \mu \mathrm{L}$ without altered performance.

On account of the linear dependence of the steady-state current with $\sqrt{\omega}$ and $C^{0}$, and on the basis of the high similarity with the circular convective flows obtained at a RDE in a confined cell (for which the Levich equation was shown to hold if the steady-state diffusion boundary layer at the working electrode is thin and buried within the hydrodynamic boundary layer), ${ }^{40}$ we have found reasonable to assume that the Levich equation also holds in the present case but, for the reasons of the peculiar hydrodynamic resistances occurring at the scale of the rotated droplet, it needs to be corrected by an appropriate empirical term in the expression of $\delta$ to take into account the $25 \%$ loss of mass transport efficiency compared to a conventional RDE. Therefore we have:

$$
i_{p l, c o r r}=\frac{n F S D C^{0}}{\delta_{\text {corr }}}=0.465 n F S D^{2 / 3} v^{-1 / 6} \omega^{1 / 2} C^{0}
$$

where $\delta_{\text {corr }}=2.15 D^{1 / 3} v^{1 / 6} \omega^{-1 / 2}$

From eq 2 and the slope of the linear fit in Figure 2B, the diffusion coefficient of $\mathrm{FcMeOH}$ can be calculated using $v=$ $0.01 \mathrm{~cm}^{2} \mathrm{~s}^{-1}$. A value of a $D=7.6 \times 10^{-6} \mathrm{~cm}^{2} \mathrm{~s}^{-1}$ was obtained which is consistent with that previously determined for FcMeOH in aqueous solution (ca. $7 \times 10^{-6} \mathrm{~cm}^{2} \mathrm{~s}^{-1}$ ), ${ }^{42,43,44}$ confirming thus the validity of eq 2 . Using this diffusion coefficient in eq 3 , a steady-state diffusion layer thickness of $12.4 \mu \mathrm{m}$ can be calculated at $\omega=2400 \mathrm{rpm}$. This value is therefore much lower than the gap height $l(2.5 \mathrm{~mm})$ and it may explain why the plateau currents are independent of the value of $l$.

When comparing the $\mathrm{CV}$ response of $5 \mu \mathrm{M} \mathrm{FcMeOH}$ at a rotated droplet to the one obtained at a classical RDE (Figure S4), it is obvious that the particularly low capacitance of the screen-printed carbon-based electrodes along with the low electrical noise resulting from the non-moving working electrode is of great interest for detecting low concentrations. This is confirmed from the calibration plot of FcMeOH (Figure S5) which shows an excellent detection limit of $0.1 \mu \mathrm{M} \mathrm{FcMeOH}$ (considering a signal-to-noise ratio of 3 and an average noise of $0.02 \mu \mathrm{A} / \mathrm{cm}^{2}$ ) combined with a good linearity (slope $=0.64$ $\mu \mathrm{A} \mathrm{cm}{ }^{-2} \mu \mathrm{M}^{-1} ; \mathrm{r}^{2}=0.996$ ), as well as good reproducibility (a relative standard deviation of $2 \%$ was obtained from 10 measurements at 10 different screen-printed electrochemical microcells).

Depending on the working electrode size, the electrode surface-to-droplet volume ratio could be relatively high in the droplet configuration and the absolute amount of molecules electrochemically transformed not negligible. To evaluate this ending, several experiments were carried out with a larger screen-printed working electrode area $\left(S=0.071 \mathrm{~cm}^{2}\right)$ and the results compared with the smaller one $\left(S=0.0177 \mathrm{~cm}^{2}\right)$ (Figure S6). The voltammetric S-shaped wave of $\mathrm{FcMeOH}$ at a larger electrode was observed to progressively and homothetically shift towards cathodic current values during successive $\mathrm{CV}$ scans $(0.1 \mathrm{~V} / \mathrm{s})$ in $50 \mu \mathrm{L} \mathrm{FcMeOH}$ solution, 
whereas for the smaller electrode the $\mathrm{CV}$ response remained practically unchanged under the same conditions. This behavior is characteristic of a significant electrolysis of $\mathrm{FcMeOH}$ in its ferrocenium form in the droplet, a direct consequence of the large electrode surface area-to-sample volume $(S / V=1.42$ $\mathrm{cm}^{-1}$ ) coupled with an efficient mass transport. The electrochemical transformation however cannot be complete, even for prolonged successive $\mathrm{CV}$ scans, because the ferrocenium produced at the working electrode during an anodic voltammetric scan can be in part reversibly reduced at the counter electrode and vice-versa (for exhaustive electrolysis at a controlled potential, the counter electrode has to be separated from the sample solution in an independent electrolyte compartment equipped with a junction ${ }^{25,26}$ ). Keeping the working electrode area-to-droplet volume ratio as low as possible is therefore essential to neglect this effect and hence get a stable signal, especially for prolonged electrode polarization. ${ }^{25}$ At the smaller working electrode, a reasonably stable signal over several tens of minutes was finally observed, which also signifies that evaporation of the aqueous droplet is negligible under these experimental conditions.

Characterization of the mixing efficiency subsequent to the injection of a reagent in the rotated droplet. The ability to electrochemically monitor the reaction progress subsequent to the injection of a reactant into the rotated reaction solution will depend on how fast is the reaction relative to the mixing. The mixing efficiency of the rotating droplet system was thus tested by manual injection of $1 \mu \mathrm{L}$ hydrogen peroxide solution into a $49 \mu \mathrm{L}$ rotated droplet while the working electrode, poised at a negative potential, was used to monitor the transient current change related to the electrochemical reduction of $\mathrm{H}_{2} \mathrm{O}_{2}$. Since the reduction of $\mathrm{H}_{2} \mathrm{O}_{2}$ is facilitated at nanoporous gold metal, ${ }^{45}$ the working carbon electrode was electroplated with a thin film of porous gold (Figure S7). The gold-plated screen-printed electrode led to an efficient reduction of $\mathrm{H}_{2} \mathrm{O}_{2}$ at $-0.6 \mathrm{~V} v s . \mathrm{Ag} / \mathrm{AgCl}$ in acidic solution. At such a negative potential, dioxygen is also reduced, giving rise to a steadystate cathodic current before addition of $\mathrm{H}_{2} \mathrm{O}_{2}$. As reported in Figure 3, upon injection of $1 \mu \mathrm{L} \mathrm{H}_{2} \mathrm{O}_{2}(50 \mathrm{mM})$ in a $49 \mu \mathrm{L}$ rotated droplet of $0.1 \mathrm{M} \mathrm{H}_{2} \mathrm{SO}_{4},(\omega=2000 \mathrm{rpm})$, the initial steady-state cathodic current density $(j)$ is instantly exponentially increased with time until to reach a maximum value $\left(j_{\max }\right)$.

This behavior is typical of an instantaneously perturbed system which exponentially relaxes with time. The exponential increase of $j$ with time was fitted to eq 4 from which a characteristic relaxation time value of $\tau=1.25 \mathrm{~s}$ was obtained.

$$
j=j_{\max }[1-\exp (-t / \tau)]
$$

The same experiment was repeated with two other aqueous media ( $0.1 \mathrm{M}$ PBS or $0.1 \mathrm{M}$ PBS containing $0.1 \%$ BSA) and similar relaxation time constants were found (Figure S8), giving an average value of $\tau=1.23 \pm 0.12 \mathrm{~s}$. This time constant characterizes the mixing time required to fully homogenize $\mathrm{H}_{2} \mathrm{O}_{2}$ in the droplet volume, a value which is here not significantly affected by the composition of the selected aqueous solutions.

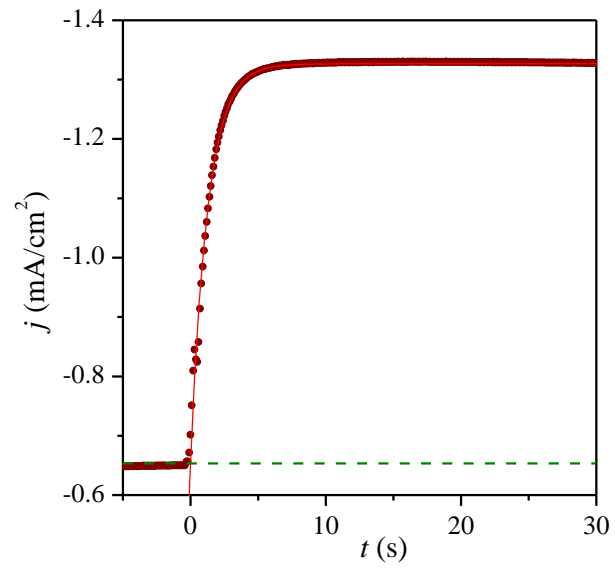

Figure 3. Transient current response obtained at a gold-plated screen-printed electrode held at $-0.6 \mathrm{~V}$ (vs. $\mathrm{Ag} / \mathrm{AgCl}$ ) during the injection $(t=0)$ of $1 \mu \mathrm{L} \mathrm{H}_{2} \mathrm{O}_{2}(50 \mathrm{mM}$ in water) in a rotated droplet $(V=49 \mu \mathrm{L}, \omega=2000 \mathrm{rpm})$ of $0.1 \mathrm{M} \mathrm{H}_{2} \mathrm{SO}_{4}$. The red line is an exponential fit to the experimental data using $\tau=1.25 \mathrm{~s}$.

Independently of the mixing time, there are three other characteristic times that may limit the temporal resolution of the kinetic method: the instrument response time, the injection time and the dead time. As mentioned in the introduction, the instrument response time (routinely in the microsecond range) is far from being rate determining in our conditions (note that even though higher sampling rate could be easily achieved in Figure 3, the current was sampled only every $100 \mathrm{~ms}$ ). Although not instantaneous, the injection time is also not rate limiting. This assertion is supported by the sharp instantaneous current increases that are sometimes observed during the first $200 \mathrm{~ms}$ subsequent to the injection of an electrodetectable reagent, but also by the perfect fit of the experimental data to a simple exponential law (Figure 3 and S8), characteristic of an instantaneously perturbed system which relaxes. Another possible rate limitation that may ensue if the injection and mixing time are instantaneous is the time required for a molecule to cross the constant diffusion layer established at the working electrode interface. This time, represented by $t \sim$ $\delta^{2} / 2 D$, is typically the dead time during which no current could theoretically be measured immediately after an injection. It is directly correlated to the rod spin rate which determines the thickness of the diffusion layer. Considering the value of $\delta=$ $17.3 \mu \mathrm{m}$ which can be calculated for $\mathrm{H}_{2} \mathrm{O}_{2}$ at $2000 \mathrm{rpm}$ using eq 3 , a dead time of $\sim 95 \mathrm{~ms}$ can be estimated (using $D_{\mathrm{H}_{2} \mathrm{O}_{2}}=$ $1.6 \times 10^{-5} \mathrm{~cm}^{2} / \mathrm{s}$ ). This rough estimation is clearly shorter than the relaxation time of $1.2 \mathrm{~s}$ determined experimentally, letting to definitely conclude that the mixing time is the rate determining factor that currently sets the kinetic time resolution of the proposed method.

Kinetic results with a bimolecular chemical reaction. As a first case study, the kinetics of the chemospecific deprotection of $p$-aminophenylboronic acid pinacol ester (PAPB) into $p$-aminophenol (PAP) by oxidative hydrolysis with $\mathrm{H}_{2} \mathrm{O}_{2}$ has been considered (Scheme 1). 

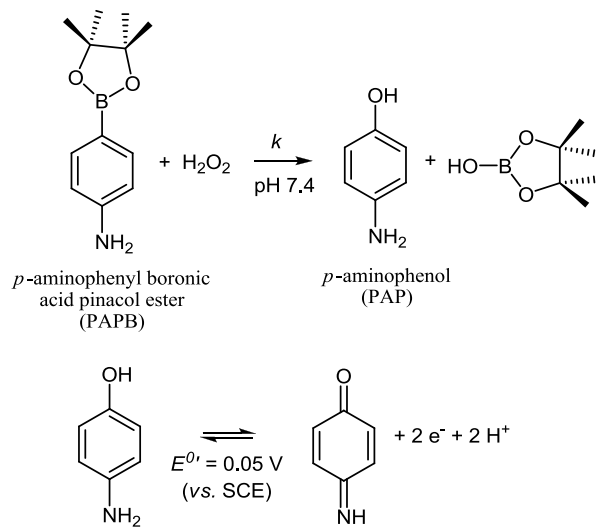

Quinoneimine

Scheme 1. Reaction scheme of the $\mathrm{H}_{2} \mathrm{O}_{2}$-mediated oxidative deprotection of PAPB into an electrooxidizable PAP product

This deprotection reaction has been recently proposed for the electrochemical determination of hydrogen peroxide generated by glucose oxidase in the presence of glucose and dioxygen. ${ }^{31}$ The electrochemical monitoring of this reaction is possible because of the distinct redox properties of the product PAP (showing a reversible oxidation at $0 \mathrm{~V}$ vs. $\mathrm{Ag} / \mathrm{AgCl}$ at $\mathrm{pH} 7.4$ ) from the starting PAPB substrate. This is illustrated in Figure 4 , where PAPB gives an irreversibly anodic peak at $+0.5 \mathrm{~V}$ in

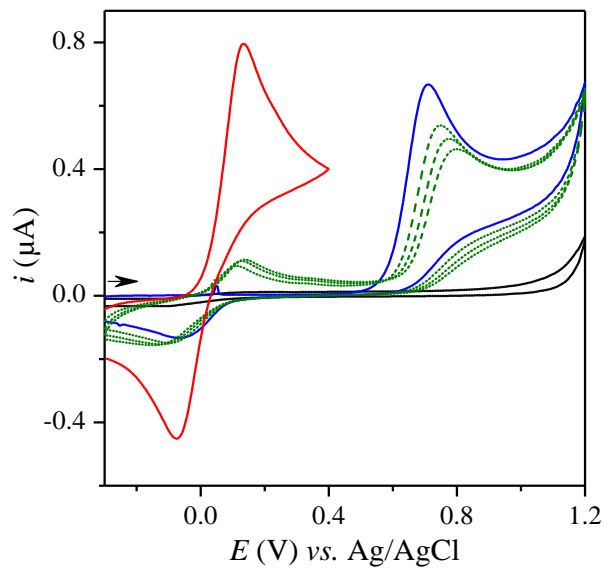

Figure 4. CVs in phosphate buffer $\mathrm{pH} 7.4$ of (blue: first scan, green: second-fourth scans) $1 \mathrm{mM}$ PAPB, (red) $1 \mathrm{mM}$ PAPB and $2.5 \mathrm{mM} \mathrm{H}_{2} \mathrm{O}_{2}$ after $10 \mathrm{~min}$ reaction time at room temperature. Scan rate: $0.05 \mathrm{~V} / \mathrm{s} . S=0.0177 \mathrm{~cm}^{2}$.

$\mathrm{CV}$, followed upon reverse scan by the appearance of a reversible wave at $\sim 0 \mathrm{~V}$ characteristic of the $p$ aminophenol/quinoneimine redox couple. For monitoring the chemical reaction of deprotection by amperometry, it is therefore essential to carefully choose the potential at which PAP is detected in order to avoid any interference from the electrochemical generation of PAP by direct oxidation of PAPB at the electrode. An applied potential of $+0.3 \mathrm{~V}$ was thus selected.

Figure 5 shows the amperometric kinetics traces obtained after the injection of different concentrations of $\mathrm{H}_{2} \mathrm{O}_{2}$ ( $C_{\mathrm{H}_{2} \mathrm{O}_{2}}^{0}$ ranging from $0.2 \mathrm{mM}$ to $10 \mathrm{mM}$ ) in a $50 \mu \mathrm{L}$ rotated droplet $(\omega=2000 \mathrm{rpm})$ of $0.1 \mathrm{mM}$ PAPB. Immediately after the addition of $\mathrm{H}_{2} \mathrm{O}_{2}(t=0)$, PAP is generated in solution and the current density at $+0.3 \mathrm{~V}$ is exponentially increased from zero up to a maximal value corresponding to the entire conversion of PAPB into PAP (current densities were normalized to this maximal value).

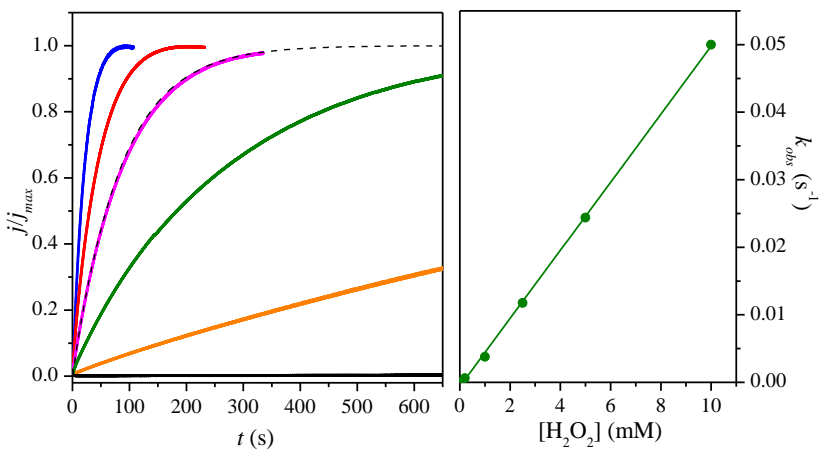

Figure 5. (Left) Normalized amperometric kinetic plots recorded at $+0.3 \mathrm{~V}$ (vs. $\mathrm{Ag} / \mathrm{AgCl})$ after the injection of $1 \mu \mathrm{L}$ of different $\mathrm{H}_{2} \mathrm{O}_{2}$ concentrations in a rotated droplet $(V=49 \mu \mathrm{L}, \omega=2000$ $\mathrm{rpm}$ ) of $0.1 \mathrm{mM}$ PAPB (in a $0.1 \mathrm{M}$ phosphate buffer, $\mathrm{pH}$ 7.4). The final concentration of $\mathrm{H}_{2} \mathrm{O}_{2}$ was (black) $0 \mathrm{mM}$, (orange) $0.2 \mathrm{mM}$, (green) $1 \mathrm{mM}$, (pink) $2.5 \mathrm{mM}$, (red) $5 \mathrm{mM}$ and (blue) $10 \mathrm{mM}$. The dashed line represents an exponential function fit to the experimental data at $2.5 \mathrm{mM} \mathrm{H}_{2} \mathrm{O}_{2}$. (Right) Pseudo-first order kinetic rate constant, $k_{o b s}$, as a function of $\mathrm{H}_{2} \mathrm{O}_{2}$ concentration. Plain line: linear regression [slope $\left.=(5.1 \pm 0.1) \mathrm{M}^{-1} \mathrm{~s}^{-1} ; \mathrm{r}^{2}=0.9994\right]$.

Given the mixing time constant of $1.2 \mathrm{~s}$ determined for $\mathrm{H}_{2} \mathrm{O}_{2}$ in the precedent part, we may thus neglect it and considered that the reaction solution is homogeneous during the whole reaction period. Under assumption of a pseudo-first order kinetic and consideration that the current is a direct measurement of the bulk concentration of PAP through eq 2, all experimental plots could thus be simply fitted by the first order rate law given by eq 5 (an illustrating example is shown in Figure 5 for the concentration of $2.5 \mathrm{mM} \mathrm{H}_{2} \mathrm{O}_{2}$ ).

$$
\frac{j}{j_{\max }}=1-\exp \left(-k_{o b s} t\right)
$$

The resulting plot of $k_{o b s}$ as a function of $C_{\mathrm{H}_{2} \mathrm{O}_{2}}^{0}$ shows a perfect linear relationship (Figure 5), confirming the bimolecular reaction mechanism. From the slope of the linear regression, the second order kinetic rate constant $k$ was inferred and a value of $5.1 \pm 0.1 \mathrm{M}^{-1} \mathrm{~s}^{-1}$ was found. This is a relatively slow rate constant that finally can be comfortably determined under our conditions. In order to corroborate this result, the rate constant was also independently determined by UVvisible spectroscopy (see Materials and Methods). A second order rate constant of $k=4.1 \pm 0.2 \mathrm{M}^{-1} \mathrm{~s}^{-1}$ was obtained, which is in good agreement with the one determined by the kinetic rotating droplet electrochemical method. The value obtained herein slightly outperforms the kinetic rate constants previously determined for $\mathrm{H}_{2} \mathrm{O}_{2}$-mediated deprotection of different types of arylboronic ester derivatives at neutral $\mathrm{pH}$ (i.e., $k$ values ranging from 0.07 to $\left.2.2 \mathrm{M}^{-1} \mathrm{~s}^{-1}\right){ }^{46,47,48,49,50}$ It probably results from a favorable electronic effect of the amino electron donating group on the para position, thereby facilitating the oxidative cleavage.

Kinetic results with the enantiospecific binding of $L$ tyrosinamide to an aptamer. As a second example, we have investigated the enantiospecific and reversible biomolecular binding kinetics of the small chiral molecule L-tyrosinamide (L-Tym) to its specific 49-mer D-deoxyribo-oligonucleotide 
aptamer (D-Apt ${ }_{49}$ ) (eq 6, considering a single binding site per aptamer).

$$
\text { L-Tym + D-Apt } 49 \text { } \underset{k_{o f f}}{\stackrel{k_{o n}}{\rightleftarrows}} \text { L-Tym/D-Apt } 49
$$

with $K_{d}=k_{o f f} / k_{o n}$

For monitoring this binding reaction, we have used the same electrochemical detection strategy we have recently developed. $^{32}$ The principle of detection relies on the intrinsic electroactive properties of L-Tym that can be oxidized at anodic potential, but also on the difference of diffusion rates between the free L-Tym molecule and the L-Tym/aptamer complex. Moreover, in order to quantitatively and accurately discriminate the free from the bound L-Tym, the elec trochemical detection was performed under redox-mediated catalysis, a strategy that not only allows to obtain well-defined and reproducible anodic catalytic currents of L-Tym, but also avoids the electrode surface fouling and/or passivation by direct oxidation of the phenol derivative. ${ }^{33,51}$ The redox-mediated catalysis was achieved under total catalysis conditions (vide infra) with the addition of minute amount of the one-electron redox mediator $\left[\mathrm{Os}^{\mathrm{II}}(\mathrm{bpy})_{3}\right]^{2+}$ in the reaction solution.

The experimental binding kinetic plots shown in Figure 6 were obtained as follow. A sandwiched $(l=2.5 \mathrm{~mm}) 48-\mu \mathrm{L}$ droplet of $5 \mu \mathrm{M}\left[\mathrm{Os}^{\mathrm{II}}(\mathrm{bpy})_{3}\right]^{2+}$ in TB was rotated at $2500 \mathrm{rpm}$, while the working screen-printed electrode potential was held at $+0.7 \mathrm{~V}$ to oxidize the $\left[\mathrm{Os}{ }^{\mathrm{II}}(\mathrm{bpy})_{3}\right]^{2+}$ into $\left[\mathrm{Os}{ }^{\mathrm{III}}(\mathrm{bpy})_{3}\right]^{3+}\left(E^{0}=\right.$ $0.58 v s$. $\left.\mathrm{Ag} / \mathrm{AgCl}^{51}\right)$. Once the steady-state anodic current was stabilized at a value of $1.9 \pm 0.2 \mu \mathrm{A} / \mathrm{cm}^{2}$, characteristic of the diffusion controlled oxidation of $\left[\mathrm{Os}{ }^{\mathrm{II}}(\mathrm{bpy})_{3}\right]^{2+52}$ a $1 \mu \mathrm{L} \mathrm{L}$ Tym solution was injected in the rotated droplet (final concentration of $C_{T y m}^{0}=5 \mu \mathrm{M}$ ). As seen in Figure 6 , immediately after L-Tym injection the current was rapidly increased to a maximal value (absolute value of $5.5 \pm 0.3 \mu \mathrm{A} / \mathrm{cm}^{2}$ ), characteristic of the catalytic oxidation of L-Tym at the electrode surface by the electrochemically generated $\left[\mathrm{Os}^{\mathrm{III}}(\mathrm{bpy})_{3}\right]^{3+}$. The rate at which the catalytic current was raised and then stabilized gives a direct measure of the mixing time required to homogeneously mix L-Tym throughout the whole droplet volume (an average relaxation time of $1.1 \pm 0.1 \mathrm{~s}$, similar to $\mathrm{H}_{2} \mathrm{O}_{2}$, was found). According to the rather high efficiency of the catalytic oxidation of L-Tym by $\left[\mathrm{Os}^{\mathrm{III}}(\mathrm{bpy})_{3}\right]^{3+}$ and also because of the low excess ratio of L-Tym compared with the redox catalyst (i.e., 1:1 ratio), the resulting steady-state catalytic current is expected to be entirely controlled by the mass transport of L-Tym to the electrode surface (i.e., total cataly$\operatorname{sis}^{53}$ ) and therefore governed by an equation similar to eq 2 . The occurrence of this limiting case was verified from the linear dependence of the steady-state catalytic current $v s$. LTym concentration within the range $0-5 \mu \mathrm{M}$ (Figure S9). ${ }^{54}$ As soon as L-Tym is well-mixed, $1 \mu \mathrm{L} \mathrm{D}-\mathrm{Apt}_{49}$ was injected $(t=$ 0 ) in the reaction solution (final $C_{A p t}^{0}$ concentration ranging from 0 to $20 \mu \mathrm{M}$ ) and the change in the catalytic current recorded. The overlaid kinetic traces in Figure 6 show a systematic exponential decay of the catalytic current subsequent to the aptamer addition until a new concentration-dependent steadystate current value is reached, characteristic of an equilibrium binding. Such a behavior is in agreement with that expected for the specific capture of L-Tym by the aptamer which hence decreases the average diffusion rate of L-Tym to the electrode. ${ }^{32}$ The concentration-dependent current decays observed over a few tens of seconds after aptamer injection (occurring thus over a time window significantly longer than the mixing time of L-Tym) are clearly related to the binding kinetic of LTym to its aptamer, whereas at longer time, the dependence of the limiting plateau current with the aptamer concentration reflects the equilibrium of the reaction $\left(K_{d}\right)$. Note that the injection of a 49-mer random DNA sequence does not produce any decrease of the catalytic current (not shown).

The general analytical expression describing the kinetics of a reversible binding reaction is obtained from the integration of eq 7 (see Supporting Information):

$$
\begin{aligned}
-\frac{d[\mathrm{~L}-\mathrm{Tym}]}{d t} & =\frac{d\left[\mathrm{~L}-\mathrm{Tym} / \mathrm{Apt}_{49}\right]}{d t} \\
& =\frac{d x}{d t}=k_{o n}\left(C_{T y m}^{0}-x\right)\left(C_{A p t}^{0}-x\right)-k_{\text {off }} x
\end{aligned}
$$

which finally leads to:

$$
\begin{aligned}
\chi_{f} & =\frac{[\mathrm{L}-\mathrm{Tym}]}{C_{T y m}^{0}} \\
& =1-\frac{1}{C_{T y m}^{0}} \frac{r_{2}-r_{1} \exp \left\{\left(r_{2}-r_{1}\right)\left[k_{o n} t+\frac{1}{r_{2}-r_{1}} \ln \left(\frac{r_{2}}{r_{1}}\right)\right]\right\}}{1-\exp \left\{\left(r_{2}-r_{1}\right)\left[k_{o n} t+\frac{1}{r_{2}-r_{1}} \ln \left(\frac{r_{2}}{r_{1}}\right)\right]\right\}}
\end{aligned}
$$

where $\chi_{f}$ is the mole fraction of L-Tym, and $r_{l}, r_{2}$ are the roots of the equation: $x^{2}-x\left(C_{T y m}^{0}+C_{A p t}^{0}+K_{d}\right)+C_{T y m}^{0} C_{A p t}^{0}=0$.

According to our previous work, ${ }^{32}$ the catalytic current $\left(i_{c}\right)$ can be considered as a linear combination of the catalytic currents related to the free and bound L-Tym, which, under approximation of total catalysis, would lead to:

$$
i_{c}=0.465 n F S v^{-1 / 6} \omega^{1 / 2} C_{T y m}^{0}\left[\chi_{f} D_{T y m}^{2 / 3}+\left(1-\chi_{f}\right) D_{T y m / A p t}^{2 / 3}\right](9)
$$

From the combination of eqs 8 and 9 and knowledge of the steady-state catalytic currents determined both in the absence of aptamer $\left(i_{c}^{0}\right)$ and at infinite aptamer concentration $\left(i_{c}^{\infty}\right)$, we can write eq 10 which allows to predict the normalized catalytic current decreases as a function of time.

$\frac{i_{c}(t)}{i_{c}^{0}}=\frac{i_{c}^{\infty}}{i_{c}^{0}}+\chi_{f}\left(1-\frac{i_{c}^{\infty}}{i_{c}^{0}}\right)$

or

$\frac{i_{c}(t)}{i_{c}^{0}}=1-\frac{1}{C_{T y m}^{0}} \frac{r_{2}-r_{1} \exp \left\{\left(r_{2}-r_{1}\right)\left[k_{o n} t+\frac{1}{r_{2}-r_{1}} \ln \left(\frac{r_{2}}{r_{1}}\right)\right]\right\}}{1-\exp \left\{\left(r_{2}-r_{1}\right)\left[k_{o n} t+\frac{1}{r_{2}-r_{1}} \ln \left(\frac{r_{2}}{r_{1}}\right)\right]\right\}}\left(1-\frac{i_{c}^{\infty}}{i_{c}^{0}}\right)$

The fit of eq 10 to the experimental data in Figure 6 would thus give the value of $k_{o n}, K_{d}$ and $i_{c}^{\infty} / i_{c}^{0}$. From the theoretical plots represented by the four dashed curves on the left graph, values of $k_{\text {on }}=5200 \mathrm{M}^{-1} \mathrm{~s}^{-1}, K_{d}=4 \mu \mathrm{M}$ and $i_{c}^{\infty} / i_{c}^{0}=0.33$ were obtained. Although fits of eq 10 to the experimental plots are almost correct, they are far from being perfect, especially at the limiting plateau currents. This is because eq 10 does not take into account the slight nonspecific steady catalytic current 


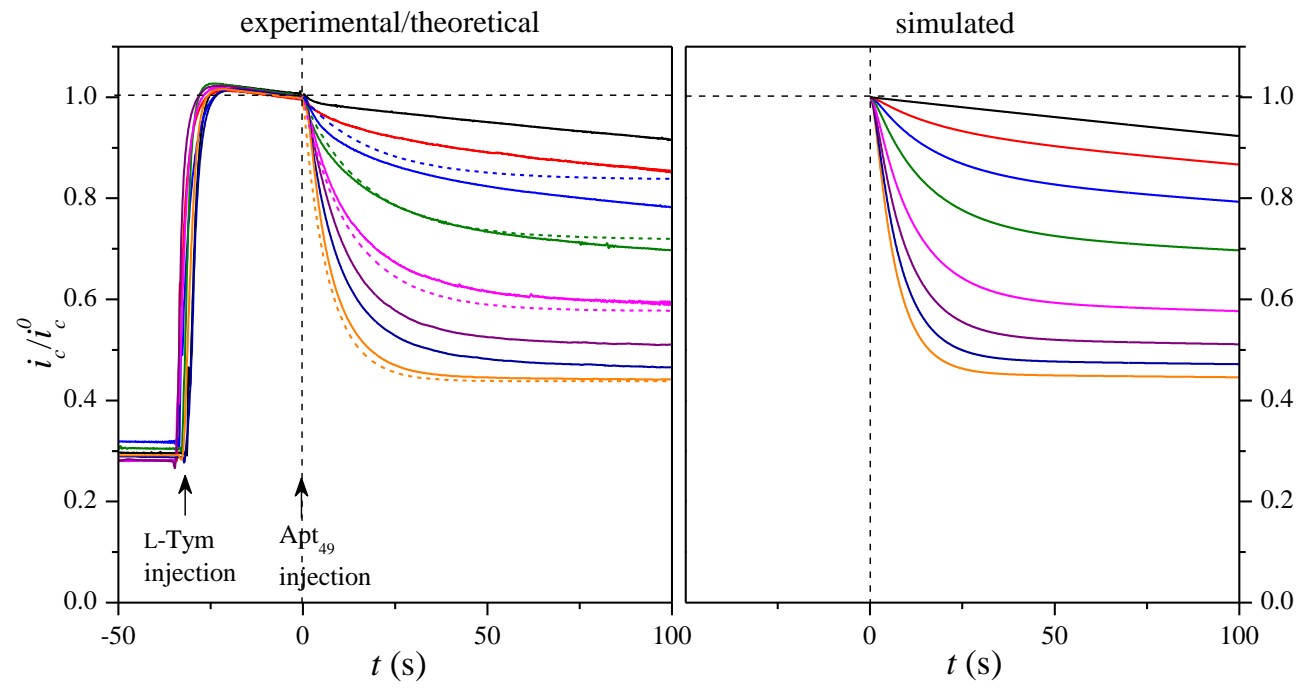

Figure 6. (Left) Normalized time-course amperometric response recorded at $+0.7 \mathrm{~V}(\mathrm{vs} . \mathrm{Ag} / \mathrm{AgCl})$ at a rotated droplet $(V=50 \mu \mathrm{L}, \omega=$ $2500 \mathrm{rpm}$ ) of $5 \mu \mathrm{M}\left[\mathrm{Os}^{\mathrm{II}}(\mathrm{bpy})_{3}\right]^{2+}$ (in TB, pH 7.4) and for successive injections of, first, $5 \mu \mathrm{M}$ L-Tym and then different concentrations of D-Apt 49 : (from top to bottom) $0,1,2.5,5,10,15,20$, and $25 \mu \mathrm{M} \mathrm{D}-\mathrm{Apt}_{49}$. The current was normalized to the catalytic current value, $i_{c}^{0}$, recorded just before the aptamer injection $(t=0)$. The dashed plots are the theoretical curves obtained from best fit of eq 10 to the data using a single set of parameters: $k_{o n}=5200 \mathrm{M}^{-1} \mathrm{~s}^{-1}, K_{d}=4 \mu \mathrm{M}$ and $i_{c}^{\infty} / i_{c}^{0}=0.33$. (Right) Simulated kinetic plots taking into account the electrocatalytic consumption of L-Tym. The simulations were obtained with the following set of parameters: $\tau=1.25 \mathrm{~s}, k_{\text {cons }}=8 \times 10^{-4} \mathrm{~s}^{-1}$, $k_{\text {on }}=5800 \mathrm{M}^{-1} \mathrm{~s}^{-1}, k_{\text {off }}=2.8 \times 10^{-2} \mathrm{~s}^{-1}$, and $i_{c}^{\infty} / i_{c}^{0}=0.33$ (see details in the text).

decrease concomitantly recorded during the course of the specific exponential response decrease. The slight steady decrease, also observed in the absence of aptamer (black curve in Figure 6), can be explained by the non-negligible irreversible consumption of L-Tym as a function of electrolysis time, with a rate that is directly related to both the electrode surfaceto-droplet volume ratio and the magnitude of the anodic catalytic current. Assuming that the measured current is governed by total catalysis and the diffusion layer thickness is steady while the sample is rotated, we can thus write eq 11 which describes the L-Tym concentration decay with time at a constant potential electrolysis:

$$
\frac{d[\mathrm{~L}-\mathrm{Tym}]}{d t}=\frac{i_{c}}{n F V}=\frac{S D}{V \delta_{\text {corr }}}[\mathrm{L}-\mathrm{Tym}]
$$

After integration, eq 11 leads to:

$$
[\mathrm{L}-\mathrm{Tym}]=C_{T y m}^{0} \exp \left[-\left(S D / V \delta_{\text {corr }}\right) t\right]
$$

or

$$
\frac{i_{c}}{i_{c}^{0}}=\frac{[\mathrm{L}-\mathrm{Tym}]}{C_{T y m}^{0}}=\exp \left(-\frac{S D^{2 / 3}}{2.15 v^{1 / 6} \omega^{-1 / 2} V} t\right)
$$

From the fit of eq 12 to the experimental curve obtained in the absence of aptamer (black curve in Figure 6), a first-order rate constant $k_{\text {cons }}=S D / V \delta_{\text {corr }}=8 \times 10^{-4} \mathrm{~s}^{-1}$ was found. When the experiment was repeated with a 4-fold larger screen-printed working electrode area $\left(S=0.071 \mathrm{~cm}^{2}\right)$, the steady catalytic current decrease was enhanced by a factor 4 (Figure S10) as expected from eq 12 .

To more rigorously take into consideration the concurrent consumption of L-Tym by aptamer binding and electrochemical oxidation during the reaction progress, the rate differential equations associated to each process were numerically solved (see Materials and Methods) and the concentration decay of LTym with time thus calculated. Also, to consider the potential interference of the mixing kinetic on the overall kinetics (especially at high aptamer concentrations), a first order mixing rate process has been included to the simulation, leading thus to the following global reaction scheme:

$$
\begin{aligned}
& \mathrm{A} \stackrel{1 / \tau}{\longrightarrow} \mathrm{D}^{-\mathrm{Apt}_{49}} \\
& \text { L-Tym } \stackrel{k_{\text {cons }}}{\longrightarrow} \mathrm{P} \\
& \text { L-Tym + D-Apt } 49 \underset{k_{\text {off }}}{\stackrel{k_{\text {on }}}{\rightleftarrows}} \text { L-Tym/D-Apt } 49
\end{aligned}
$$

where A represents the aptamer amount initially present in the micropipette and $\mathrm{P}$ the product generated from the irreversible transformation of L-Tym. ${ }^{55}$ This whole set of reactions need thus five parameters to simulate and fit the progress curves shown in Figure 6, i.e. $\tau, k_{\text {cons }}, k_{\text {on }}, k_{\text {off }}$ and $i_{c}^{\infty} / i_{c}^{0}$. The first two constants, $\tau$ and $k_{\text {cons }}$, were recovered from the previous experiments. The three others were adjusted by iterative fitting of the simulated plots to the experimental ones. From the best fits (Figure 6, right plots), the following values were obtained: $k_{\text {on }}$ $=5800 \pm 200 \mathrm{M}^{-1} \mathrm{~s}^{-1}, k_{\text {off }}=0.028 \pm 0.003 \mathrm{~s}^{-1}$ and $i_{c}^{\infty} / i_{c}^{0}=0.33$ \pm 0.02 . The resulting $K_{d}=k_{\text {off }} / k_{\text {on }}=4.8 \pm 0.3 \mu \mathrm{M}$ is consistent with our previous work (i.e., $K_{d}=2.9 \mu \mathrm{M}$ ) 32 and in agreement with those previously determined by isothermal titration calorimetry $^{56}$ and fluorescence polarization, ${ }^{57}$ therefore validating the reliability of the method. From the experimental ratio $i_{c}^{\infty} / i_{c}^{0}=0.33$ proportional to $\left(D_{T y m / A p t} / D_{T y m}\right)^{2 / 3}$, the calculated value of $D_{T y m / A p t} / D_{T y m}=0.19$ also compares well to the one (i.e., 0.20) previously found by CV under non- 
hydrodynamic conditions (in this latter case $\left.i_{c}^{\infty} / i_{c}^{0}=\left(D_{\text {Tym } / \text { Apt }} / D_{\text {Tym }}\right)^{1 / 2}\right) .^{32}$

Knowing the binding kinetics between aptamers and small ligands is important for understanding their recognition mechanisms as well as for developing practical affinity binding assays. A number of studies have been devoted to this end and, when compared with the rate constants that have been previously determined for small molecule interactions with natural or unnatural aptamers, ${ }^{8,58,59,60,61}$ the value obtained here $\left(k_{\text {on }}=5800 \mathrm{M}^{-1} \mathrm{~s}^{-1}\right)$ lies in the average of published values. For instance, a binding rate constant of $k_{\text {on }}=2 \times 10^{4} \mathrm{M}^{-1} \mathrm{~s}^{-1}$ has been found for the specific interaction between the thiamine pyrophosphate ligand and the RNA riboswitch present in the 5'-UTR of the thiC mRNA, ${ }^{8}$ a result that was obtained by kinetic isothermal titration calorimetry. This technique is more universal than ours but requires an expensive instrument currently restricted to a response time of $\sim 3.5 \mathrm{~s}^{8}$ Another example that has been recently investigated by kinetic capillary electrophoresis is the interaction of quinine with variants of a DNA aptamer for which $k_{\text {on }}$ values ranging from 340 to $410 \mathrm{M}^{-1} \mathrm{~s}^{-1}$ have been found. ${ }^{58}$ The kinetic capillary electrophoresis method has the advantage of not requiring the labeling of one reactant and it can then be applied theoretically to all types of ligands. ${ }^{58}$ However in practice, the technique is limited by the buffer composition that may perturb the electro-osmotic flow and also by charged ligands that can interact and be retained on the capillary wall. The other examples of $k_{o n}$, ranging from $2 \times 10^{4}$ to $2 \times 10^{5} \mathrm{M}^{-1} \mathrm{~s}^{-1}$, were all determined by stopped-flow fluorescence spectroscopy. ${ }^{59-61}$ The main advantage of this technique is that it allows the determination of fast binding rate constants because of its millisecond time resolution combined with a good sensitivity. However, this is once more a rather costly instrument which requires large amount of biological material for performing a complete set of kinetic experiments. In contrast to all of these examples, the present kinetic method has finally the combined advantages of being affordable, simple, really easy to implement and using very low amount of reagents, which is particularly interesting for some natural nucleic acids that can only be produced in low amount by in vivo genetic expression. The electrochemical detection here profits from the intrinsic electroactivity of the ligand but it can be also extended to non-electroactive ligands by introducing an extrinsic redox label on the ligand as we have previously shown with a ferrocene-labeled L-Tym. ${ }^{32}$ Besides, kinetic characterization of strictly non-modified ligand might also be carried out by combing redox labeling strategies with competitive bindings. ${ }^{32}$ Another general aspect of the present technique lies in the fact that the maximal signal amplitude between free and bound state is merely set by the relative change in diffusion coefficients, therefore leading to a predictable signal change for any new design of a small target/aptamer binding assay. This is undeniably an advantage over unpredictable signal change generated by fluorescent probes in optical detection methods."

Kinetic results with the reversible substrate inhibition of horseradish peroxidase. As a last illustrating example, we have investigated the kinetics of a more complex reaction mechanism: the catalytic reduction of $\mathrm{H}_{2} \mathrm{O}_{2}$ by horseradish peroxidase (HRP). This mechanism was previously elucidated by cyclic voltammetry under redox-mediated catalysis. ${ }^{33}$ The reaction scheme is recalled in Scheme 2 where $\mathrm{P}$ and $\mathrm{Q}$ are the oxidized $\left(\left[\mathrm{Os}^{\mathrm{III}}(\mathrm{bpy})_{2} \mathrm{pyCl}^{2+}\right)\right.$ and reduced $\left(\left[\mathrm{Os}^{\mathrm{II}}(\mathrm{bpy})_{2} \mathrm{pyCl}\right]^{+}\right)$ forms of the reversible one-electron redox cosubstrate (or mediator), $\mathrm{E}$ is the native ferriperoxidase, $\mathrm{E}_{1}$ the oxyferryl $\pi$ cation radical compound $\mathrm{I}, \mathrm{E}_{2}$ the oxyferryl compound II, $\mathrm{E}_{3}$ the oxyperoxidase compound III, and $\mathrm{ES}$ and $\mathrm{E}_{2} \mathrm{Q}$, the precursor complexes that may take place with the reactive form of substrate and cosubstrate, respectively. In the presence of substrate $\mathrm{H}_{2} \mathrm{O}_{2}$, the catalytic cycle starts from a rapid oxygen atom transfer (reaction 1) from $\mathrm{H}_{2} \mathrm{O}_{2}$ to the ferric heme ( $\mathrm{Fe}{ }^{\mathrm{III}}$ ) in $\mathrm{E}$ (formally a $2 \mathrm{e}^{-}$oxidation) to form water and the intermediate $\mathrm{E}_{1}$. Since this first reaction step goes through the formation of a short-lived ES intermediate, it can be kinetically described by a Michaelis-Menten formalism and the following two key parameters: a substrate Michaelis constant $K_{l, M}=\left(k_{l,-1}\right.$ $\left.+k_{l, 2}\right) / k_{l, 1}=128 \mu \mathrm{M}$ and a bimolecular rate constant $k_{l}=$ $k_{l, 1} k_{l, 2} /\left(k_{l,-1}+k_{l, 2}\right)=1.7 \times 10^{7} \mathrm{M}^{-1} \mathrm{~s}^{-1}$. In the presence of a oneelectron donor $\mathrm{Q}, \mathrm{E}_{1}$ is then rapidly reduced to yield the oxyferryl intermediate $\mathrm{E}_{2}$ and the product $\mathrm{P}$ (reaction 2). Thereafter, with a second equivalent of $\mathrm{Q}$, the enzyme is regenerated back to its native resting state $\mathrm{E}$ by a subsequent one-electron/two-proton reduction of $E_{2}$ to give a second equivalent of $\mathrm{P}$ and water (reaction 3 ). At sufficiently high substrate concentration, this third reaction is generally the rate limiting step of the catalytic cycle of HRP (reaction 2 is 10 to 20 -fold faster than reaction 3). ${ }^{33,62}$ Moreover, its investigation has shown kinetic evidences for a two-step Michaelis-Mententype reaction with a wide range of electron donnors, ${ }^{63,64}$ a behavior that was also observed with $\left[\mathrm{Os}^{\mathrm{II}}(\mathrm{bpy})_{2} \mathrm{pyCl}\right]^{+}$for which a cosubstrate Michaelis constant of $K_{3, M}=\left(k_{3,-1}+\right.$ $\left.k_{3,2}\right) / k_{3,1}=20 \mu \mathrm{M}$ and a bimolecular rate constant of $k_{3}=$ $k_{3,1} k_{3,2} /\left(k_{3,-1}+k_{3,2}\right)=1.4 \times 10^{7} \mathrm{M}^{-1} \mathrm{~s}^{-1}$ were obtained. ${ }^{33}$ The main loop $\mathrm{E} \rightarrow \mathrm{E}_{1} \rightarrow \mathrm{E}_{2} \rightarrow \mathrm{E}$ is the well-established peroxidatic catalytic cycle of $\mathrm{HRP}$, during which one molecule of $\mathrm{H}_{2} \mathrm{O}_{2}$ is

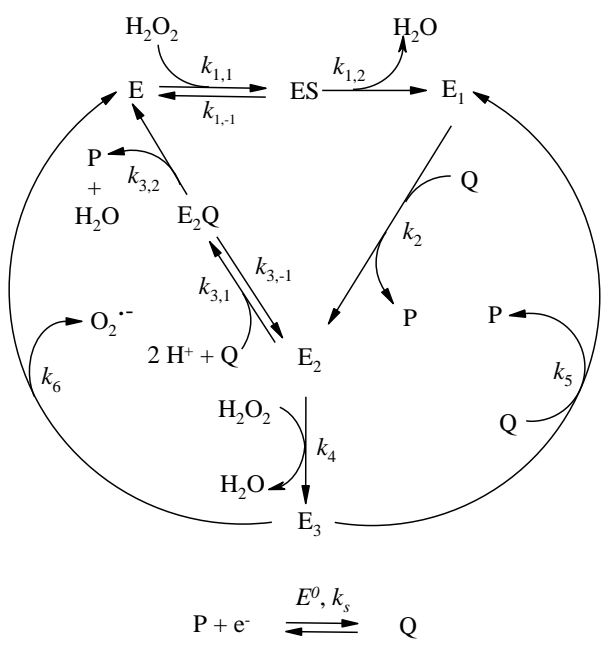

\section{Scheme 2. Global redox-mediated catalytic reaction mechanism of HRP.}

converted in two molecules of $\mathrm{H}_{2} \mathrm{O}$ while two molecules of a one-electron donor are concomitantly oxidized. This fast primary catalytic cycle is the source of the amplified catalytic current in cyclic voltammetry. ${ }^{33}$ However, at high $\mathrm{H}_{2} \mathrm{O}_{2}$ concentration, the intermediate $\mathrm{E}_{2}$ can competitively react with $\mathrm{H}_{2} \mathrm{O}_{2}$ (reaction 4) to yield the inactivated form of HRP, the oxyperoxidase or $\mathrm{E}_{3}$ (with a rate constant $k_{4}$ ranging from 16 to $\left.55 \mathrm{M}^{-1} \mathrm{~s}^{-1}\right),{ }^{65,66,67}$ resulting in a catalytic current inhibition. ${ }^{33}$ Additional complexity also comes from the two HRP reactivation pathways via $\mathrm{E}_{3}$. The first one is the spontaneous selfreactivation by decomposition of $\mathrm{E}_{3}$ into the active form $\mathrm{E}$ 
(reaction 6), leading to superoxide ion with a rate constant $k_{6}$ ranging from $2.2 \times 10^{-3}$ to $1.2 \times 10^{-2} \mathrm{~s}^{-1}{ }^{33,67,68}$ The second one is the reductive reactivation of $E_{3}$ into $E_{1}$ by the electron donor $\mathrm{Q}$ present in solution (reaction 5). ${ }^{69,70} \mathrm{~A}$ rate constant $k_{5}$ of $1900 \mathrm{M}^{-1} \mathrm{~s}^{-1}$ was previously found for the reactivation of $E_{3}$ by the $\left[\mathrm{Os}^{\mathrm{II}}(\mathrm{bpy})_{2} \mathrm{pyCl}^{+}\right.$complex. $^{33}$

In a previous work, ${ }^{33}$ the whole set of kinetic constants controlling the inactivation/reactivation reactions of HRP were determined from the analysis of catalytic responses recorded by $\mathrm{CV}$ under stationary conditions. The present rotating droplet kinetic method offers the opportunity to reexamine these inactivation/reactivation pathways not only under hydrodynamic conditions but also transiently subsequent to the injection of $\mathrm{H}_{2} \mathrm{O}_{2}$. For such a purpose, a $49 \mu \mathrm{L}$ droplet containing 1 $\mu \mathrm{M}$ HRP and $20 \mu \mathrm{M}$ [Os ${ }^{\text {II }}(\mathrm{bpy})_{2} \mathrm{pyCl}^{+}$(in $\mathrm{EB}, \mathrm{pH}$ 7.4) was rotated at $\omega=2000 \mathrm{rpm}$ over a screen-printed electrochemical cell. The potential of the working electrode was held first at an anodic value of $+0.4 \mathrm{~V}$ followed by a rapid switch at $-0.1 \mathrm{~V}$ before then an aliquot of $\mathrm{H}_{2} \mathrm{O}_{2}$ was added. The electrode polarization at $+0.4 \mathrm{~V}$ provides a steady-state current resulting from the oxidation of the osmium(II) complex present in the droplet and thereby lets to control if the concentration and hydrodynamic conditions are right (Figure 7). From the steady-state current, the diffusion coefficient of $\left[\mathrm{Os}^{\mathrm{II}}(\mathrm{bpy})_{2} \mathrm{pyCl}\right]^{+}$can also be determined using eq 3 . An average value of $D_{Q}=4.5 \times 10^{-6}$ $\mathrm{cm}^{2} \mathrm{~s}^{-1}$ was obtained, which is in good agreement with that previously published. ${ }^{33}$ Upon switching the electrode potential at $-0.1 \mathrm{~V}$, the current density drops to zero since at this potential the complex remains in its reduced form $\left(E_{P / Q}^{0}=0.21 \mathrm{~V}\right)$. Immediately after addition of $1 \mu \mathrm{L} \mathrm{H}_{2} \mathrm{O}_{2}$ solution $(t=0$, final concentration ranging from 0.01 to $50 \mathrm{mM}$ ), the cathodic current is rapidly and exponentially raised in less than $1.5 \mathrm{~s}$ (which is characteristic of the mixing time), up to a maximal value which depends on the injected $\mathrm{H}_{2} \mathrm{O}_{2}$ concentration (Figure 7). This fast increase of the catalytic current is concomitant to the rapid and complete oxidation of the reduced form of the osmium complex in the droplet, whereas a stoichiometric amount of $\mathrm{H}_{2} \mathrm{O}_{2}$ is simultaneously consumed. Once the maximum is reached, the current is decreased in a $\mathrm{H}_{2} \mathrm{O}_{2^{-}}$ concentration dependent manner until a steady-state value is asymptotically reached at longer time (Figure 7). This behavior is characteristic of the reversible inhibition of HRP by its substrate $\mathrm{H}_{2} \mathrm{O}_{2}$ which, according to reaction 4 in Scheme 2, follows a second order rate with the $\mathrm{H}_{2} \mathrm{O}_{2}$ concentration. During the course of the catalytic reduction of $\mathrm{H}_{2} \mathrm{O}_{2}$ by $\mathrm{HRP}, \mathrm{E}_{2}$ is progressively deviated from the primary catalytic loop through the competitive reaction 4 which thus allows $\mathrm{E}_{3}$ to be accumulated. However, while $\mathrm{E}_{3}$ is accumulated, a fraction is reactivated through reactions 5 and 6. As observed in Figure 7, once the inhibition rate equals those of reactivation, the catalytic current stops at a stationary value which thus depends on the $\mathrm{H}_{2} \mathrm{O}_{2}$ concentration according to the following competitive parameter: $k_{4} C_{S}^{0} /\left(k_{5}[\mathrm{Q}]+k_{6}\right)$ (where $C_{S}^{0}$ is the droplet concentration of $\mathrm{H}_{2} \mathrm{O}_{2}$ and [Q] the concentration of $\left[\mathrm{Os}^{\mathrm{II}}(\mathrm{bpy})_{2} \mathrm{pyCl}\right]^{+}$generated within the diffusion-reaction layer at the electrode surface). When only a stoichiometric amount of $\mathrm{H}_{2} \mathrm{O}_{2}$ is added $\left(10 \mu \mathrm{M} \mathrm{H}_{2} \mathrm{O}_{2}\right.$ for $20 \mu \mathrm{M}$ osmium(II) complex, wine curve in Figure 7), the cathodic current slowly increases over seconds and then halts at an absolute value not very different to the one obtained for the steady-state oxidation of $\left[\mathrm{Os}^{\mathrm{II}}(\mathrm{bpy})_{2} \mathrm{pyCl}\right]^{+}$at $+0.4 \mathrm{~V}$ (note that at these concentrations, substrate inhibition is negligible). This behavior is characteristic of quantitative conversion of the osmium(II) complex initially present in the droplet into its osmium(III) form. The measured current here provides an immediate observation of the osmium(III) concentration growth within the droplet through the primary peroxidatic catalytic loop of HRP. The rate at which this process occurs is in fact largely controlled by the mixing rate because, on the basis of the kinetic rate constants that were previously determined for the primary catalytic cycle, ${ }^{33}$ the time required for complete enzymatic conversion of the osmium(II) at the present micromolar concentrations is theoretically less than $0.5 \mathrm{~s}$ (Figure S11). After a few seconds of reaction, the resulting steady-state cathodic current reflects the reduction of the osmium(III) from which the diffusion coefficient $D_{P}$ can be retrieved. Assuming that the $20 \mu \mathrm{M}$ osmium(II) complex in the droplet is entirely converted into osmium(III), a value of $D_{P}=3.2 \times 10^{-6} \mathrm{~cm}^{2} \mathrm{~s}^{-1}$ can be calculated, which is slightly lower than that for the parent reduced form. It is interesting to note that the rather long time (several seconds) needed to reach the steady-state current compared to the predicted one (less than $0.5 \mathrm{~s}$ ), wellillustrating the prejudicial effect of the delay imposed by the non-instantaneous mixing (the catalytic reaction rate is in fact convoluted to the mixing rate since both kinetics are of same order of magnitude, therefore delaying the complete conversion of osmium(II) into osmium(III)) (see simulations in Figure S11).

In an attempt to analyze the experimental kinetics plots through an analytical expression of the catalytic current changes as a function of time (i.e. in a similar way as it was previously done in cyclic voltammetry ${ }^{33}$ ), we have realized its unfeasibility for the reason that, under our experimental settings, the catalytic current never reaches pure catalytic kinetic conditions (the thickness of the catalytic enzyme reaction layer is in fact of comparable size to the thickness of the steadystate diffusion layer of the redox mediator, even for the highest catalytic current response). ${ }^{71}$ The alternative was then to numerically solve the overall rate differential equations of the HRP mechanism with the help of the commercial DigiElch software dedicated to the simulation of electrochemical processes at electrodes by finite difference computation. ${ }^{38}$ Since DigiElch does not allow simulating an electrochemical response at a RDE, we have selected the chronoamperometric 2D-simulation mode at a microdisk electrode which lets to simulate a current response under steady-state mass transport conditions equivalent to those achieved at a RDE. In addition to the overall elementary reactions of HRP reported in Scheme 2 , the mixing rate was included in the simulation via a first order reaction in which $\mathrm{H}_{2} \mathrm{O}_{2}$ is generated from a virtual compound $U$ with a rate constant of $1 / \tau=0.8 \mathrm{~s}^{-1}$. The overall parameters that give best fits to the experimental plots in Figure 7 are reported in Table 1. For the fitting, only the rate constants $k_{4}, k_{5}$ and $k_{6}$ were slightly adjusted whereas the other rate constants were kept the same than in previous work. ${ }^{33}$ Using this set of values, the time-course amperometric simulations were finally found, for all substrate concentrations, in excellent agreement with the experimental ones (right plots in Figure 7). Even for the experiment performed under stoichiometric $\mathrm{H}_{2} \mathrm{O}_{2}$ /mediator ratio, the current response is well predicted by simulation. These results again demonstrate the relevance of the kinetic rotating droplet electrochemical method for reaction progress kinetic analysis in microliter samples and highlight the potentialities offered by this method for analyzing kinetics of complex mechanisms. It also point out to its high precision, resolution and reproducibility. 


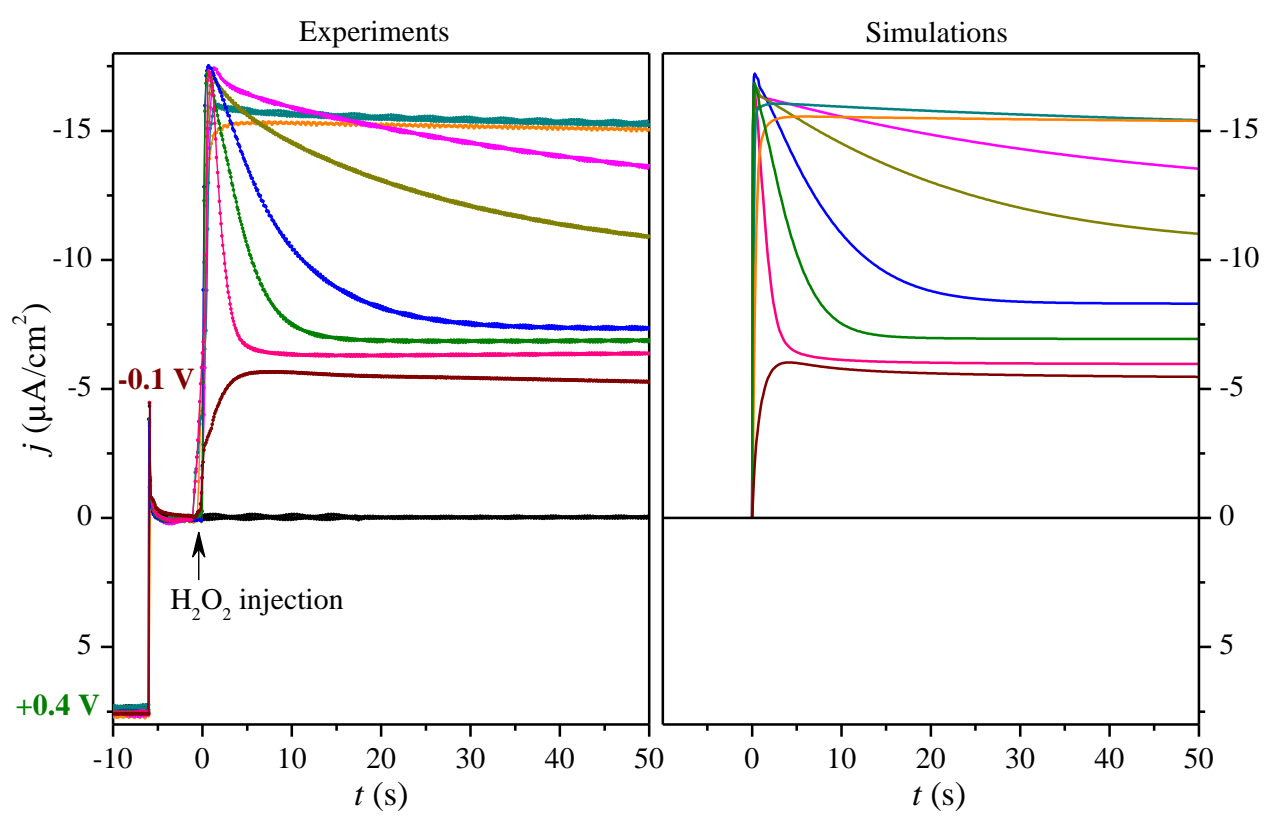

Figure 7. (Left) Substrate-inhibition kinetics of HRP recorded at a $50 \mu \mathrm{L}$ droplet $(\omega=2000 \mathrm{rpm})$ rotated over an electrode polarized first at $+0.4 \mathrm{~V}$ for $20 \mathrm{~s}$ (only the last $8 \mathrm{~s}$ are shown) and then at $+0.1 \mathrm{~V}$, before then an aliquot of $\mathrm{H}_{2} \mathrm{O}_{2}$ is injected at $t=0$. The starting composition of the droplet is $20 \mu \mathrm{M}\left[\mathrm{Os}^{\mathrm{II}}(\mathrm{bpy})_{2} \mathrm{pyCl}\right]^{+}+1 \mu \mathrm{M} \mathrm{HRP}$ in $\mathrm{EB}\left(\mathrm{pH}\right.$ 7.4). At time $t=0$ (arrow), $\mathrm{H}_{2} \mathrm{O}_{2}$ was injected in the droplet in such a way to have a final substrate concentration of: (black) $0 \mathrm{mM}$, (wine) $0.01 \mathrm{mM}$, (orange) $0.04 \mathrm{mM}$, (dark cyan) $0.1 \mathrm{mM}$, (magenta) 0.4 mM, (dark yellow) $1 \mathrm{mM}$, (blue) $4 \mathrm{mM}$, (green) $10 \mathrm{mM}$ and (pink) $50 \mathrm{mM}$. (Right) Corresponding simulated curves (see text for details).

Table 1. Kinetic rate constants and parameters used for the simulation of the redox-mediated catalytic responses of HRP shown in Figure 7 (In parentheses are the values reported in ref 33).

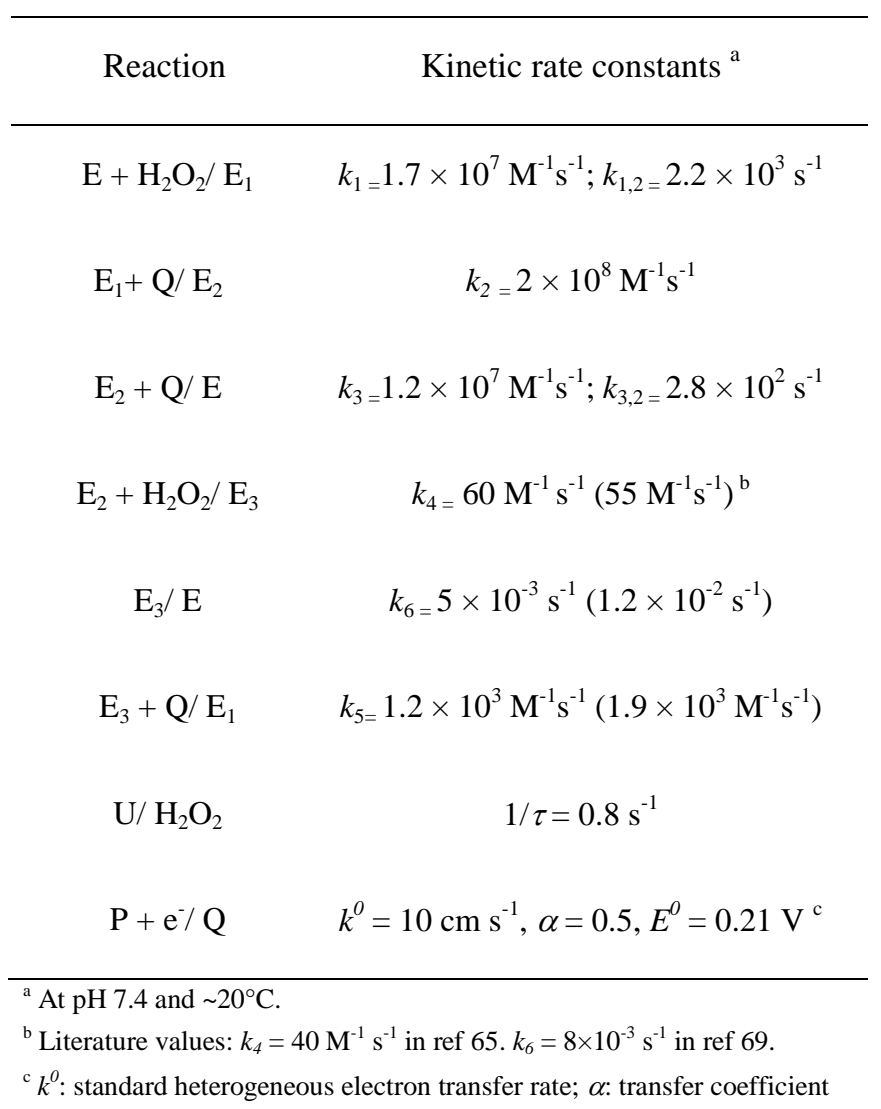

\section{CONCLUSION}

In this proof-of-principle work, we have outlined the main features of the kinetic rotating droplet electrochemical method. Its one-second kinetic time resolution combined with a low detection limit, high reproducibility, ease-to-operate, and ability to perform kinetics with microliter-size samples are key advantages that make this methodology particularly attractive and appropriate for kinetic analysis, especially for reactions involving low-abundant and/or expensive reagents.

The method has been currently illustrated with three different types of reactions: an irreversible chemical reaction, a reversible biomolecular recognition binding, and a substrate inhibition/reactivation of a catalytic enzyme reaction. It is of course not restricted to these reaction types. In principle, it can be extended to any homogeneous reactions involving a change either in the redox state, formal potential, electron transfer kinetics, or diffusion rate of one of the reactants or products. Although not demonstrated here, on the basis of our previous work involving a redox labeling strategy, ${ }^{32}$ the method can also be anticipated for kinetic characterizations of reactions which do not directly implicate an electrodetectable compound. Furthermore, the methodology can be extended to reactions occurring heterogeneously at an electrode surface. For example, it could be used for studying heterogeneous electrochemical catalytic reactions at electrodes modified by molecular or inorganic catalysts, but also for characterizing catalytic reactions of immobilized enzymes (either through direct or mediated electron transfer) on different type and/or shape of conductive materials (e.g., nanostructured conductive materials, forests of nanotubes, transparent conductive metal oxides, ...), or for investigating either the adsorption kinetics of electroactive compounds on electrode surfaces or the specific binding of a ligand to an immobilized receptor in a much 
easier way than at a conventional RDE. For these latter applications, the cell volume is no more an issue but the possibility to easily adapt/interchange the nature and/or shape of the working electrode is of great interest, especially for investigating under hydrodynamic conditions the heterogeneous electrochemical reactions at fragile electrode materials or at electrodes having complex design and/or shapes.

While the use of screen-printed technology allows flexible design (geometries and materials) of disposable and miniaturized electrochemical cells, particularly well-adapted to the method, electrochemical microcells fabricated by other techniques such as photolithography ${ }^{72}$ and laser micromachining ${ }^{73}$ might also be straightaway used. Another much appreciated feature of the method is the very easy and fast sample change which just needs to remove the droplet by pipetting and, after washing electrodes/rod interface and soaking up with a paper tissue, to apply a new one. The system was demonstrated with aqueous droplets but it can be relatively easily transposed to any low-volatile organic solvent able to form a stable hemispherical droplet on a surface delimited by an appropriate circular well. The foregoing features along with the ease-toimplement the system in a laboratory from the commercially available standard potentiostats and adjustable speed rotators is a further reason that makes the method accessible and attractive.

In the case of large electrode surface area to volume ratio, exhaustive electrolysis of the electroactive species in the entire sample droplet has been shown achievable. It therefore opens the opportunity to determine reaction stoichiometries by microcoulometry as well as to analyze the electrolyzed content of the microdrop by separation methods (e.g., HPLC, capillary electrophoresis ...). For the development of these applications, the problem of isolating the counter electrode in an independent compartment separated from the droplet by a junction has to be solved. One possibility is to include, similarly as shown by Gratzl and coll, ${ }^{25,26}$ a junction (e.g., Vycor glass frit) with an electrolyte compartment somewhere on the nonmoving support of the working electrode. Another more convenient approach would be to incorporate the counter electrode directly inside the body of a hollow rotating rod filled with an electrolyte and closed at its disk extremity with a junction.

Additionally, independently of microcoulometric and kinetic applications, the rotating droplet system could be advantageously used for a wide range of analytical purposes (e.g., electrochemical enzyme-based bioaffinity assays, anodic stripping voltammetry of heavy metals ...).

The work is in progress to improve the mixing time down to a few tens of milliseconds and to better understand the mass transport occurring at the rotated droplet/stationary working electrode interface from numerical simulations. Mechanical increase of the mixing by trapping small air-bubbles within the rotated droplet or by using a roughened rotating rod interface are directions that must be considered to improve the mixing time of the system. Designing a device able to perform fast non-manual injection at a well-defined position in the droplet is another route to explore.

We believed that the kinetic rotating droplet electrochemical method is not only an alternative as well as a complementary method to the wide range of existing optical kinetic methods, but also offers new possibilities for getting information unattainable by other simple means.

\section{ASSOCIATED CONTENT}

Supporting Information. Figures S1-S10 showing crosssectional profile of the screen-printed electrochemical microcell, $\mathrm{CVs}$ for a low $\mathrm{FcMeOH}$ concentration at a rotated droplet, $\mathrm{CV}$ comparison with a standard RDE, detection sensitivity of $\mathrm{FcMeOH}$, effect of electrode area on successive CV scans at a rotated droplet, SEM images of a gold-plated screen printed electrode, transient currents characterizing the mixing time, verification of the linear relationship between catalytic current and L-Tym concentration, influence of electrode area on the catalytic current of L-Tym, and simulations of $[\mathrm{Q}]$ decay or $[\mathrm{P}]$ growth during redox-mediated HRP catalysis. Derivation of eq 7 is also reported. This material is available free of charge via the Internet at http://pubs.acs.org.

\section{AUTHOR INFORMATION}

\section{Corresponding Authors}

francois.mavre@univ-paris-diderot.fr; limoges@univ-parisdiderot.fr

\section{Author Contributions}

tThese authors contributed equally.

\section{Notes}

The authors declare no competing financial interests.

\section{ACKNOWLEDGMENT}

This work was supported by Agence Nationale pour la Recherche (ANR ECSTASE project).

\section{ABBREVIATIONS}

$\mathrm{RDE}$, rotating disk electrode; HRP, horseradish peroxidase; $\mathrm{CV}$, cyclic voltammetry; $\mathrm{FcMeOH}$, ferrocene methanol; PAPB, $p$ aminophenylboronic acid pinacol ester; PAP, $p$-aminophenol. 


\section{REFERENCES}

1. Blackmond, D. G. Angew. Chem. Int. Ed., 2005, 44, 4302-20.

2. Roder, H.; Maki, K.; Cheng, H.; Shastry, M. C. Methods, 2004, 34, 15-27.

3. Hargrove, M. S. Methods Mol Biol., 2005, 305, 323-42.

4. Roder, H.; Maki, K.; Cheng, H. Chem. Rev., 2006, 106, 1836-61.

5. Eccleston, J. F.; Martin, S. R.; Schilstra, M. J. Methods Cell Biol., 2008, 84, 445-77.

6 Balbach, J.; Forge, V.; van Nuland, N. A. J.; Winder, S. L.; Hore, P. J.; Dobson, C. M. Nat. Struct. Biol., 1995,2 , 865.

7. Christianson, M. D.; Tan, E. H. P.; Landis, C. R. J. Am. Chem. Soc., 2010, 132, 11461-63.

8. Burnouf, D.; Ennifar, E.; Guedich, S.; Puffer, B.; Hoffmann, G.; Bec, G.; Disdier, F.; Baltzinger, M.; Dumas, P. J. Am. Chem. Soc., 2012, 134, 559-65.

9. Segel, D. J.; Bachmann, A.; Hofrichter, J.; Hodgson, K. O.; Doniach, S.; Kiefhaber, T. J. Mol. Biol., 1999, $288,489-99$.

10. Han, Z.; Li, W.; Huang, Y.; Zheng, B. Anal. Chem., 2009, 81, 5840-5.

11. van Stroe-Biezen, S. A.M.; Janssen, A. P.M.; Janssen, L. J. J. Bioelectron. Bioenerg., 1994, 33, $55-60$.

12. Léger, C.; Dementin, S.; Bertrand, P.; Rousset, M.; Guigliarelli, B. J. Am. Chem. Soc., 2004, 126, $12162-72$.

13. Bourdillon, C.; Demaille, C.; Moiroux, J.; Savéant, J-M. J. Am. Chem. Soc., 1999, 121, 2401-8.

14. Anne, A.; Chovin , A.; Demaille, C. Langmuir, 2012, 28, 8804-13.

15. Liu, Y.; Irving, D.; Qiao, W.; Ge, D.; Levicky, R. J. Am. Chem. Soc., 2011, 133, 11588-96.

16. Bard, A. J.; Faulner, L. R., Electrochemical Methods. Fundamentals and Applications, John Wiley \& Sons Inc., 2001.

17. Banks, C. E.; Simm, A. O.; Bowler, R.; Dawes, K.; Compton; R. G. Anal. Chem., 2005, 77, $1928-30$.

18. Macpherson, J. V.; Simjee, N.; Unwin, P. R. Electrochim. Acta, 2001, 47, 29-45.

19. Lee, H. J.; Fermin, D. J.; Corn, R. M.; Girault, H. H. Electrochem. Commun., 1999, 1, 190.

20. Alden, J. A.; Hakoura, S.; Compton, R. G. Anal. Chem., 1999, 71, 806-10.

21. Melville, J. L. Simjee, N.; Unwin, P. R.; Coles, B. A.; Compton, R. G. J. Phys. Chem. B, 2002, 106, 10424-31.

22. Mount, A. R., Hydrodynamic Electrodes in Encyclopedia of Electrochemistry, Wiley-VCH Verlag GmbH \& Co. KGaA, 2007.

23. Villullas, H. M.; Teijelo, M. L. J. Electroanal. Chem., 1995, 384, 25-30.

24. Villullas, H. M.; Teijelo, M. L. J. Electroanal. Chem., 1995, 385, 39-44.

25. Cserey, A.; Gratzl, M. Anal. Chem., 1997, 69, 3687-92.

26. Shetty, G. N.; Syed, N.; Tohda, K.; Gratzl, M. Anal. Sci., 2005, 21, 1155-60.

27. Wijayawardhana, C. A.; Halsall, H. B.; Heineman, W. R. Anal. Chim. Acta, 1999, 399, 3-11.

28. Thomas, J. H.; Ronkainen-Matsuno, N. J.; Farrell, S.; Halsall, H. B.; Heineman, W. R. Microchem. J., 2003, 74, $267-6$.

29. Kuramitz, H.; Halsall, H. B.; Heineman, W. R. Anal. Methods, 2012, 4, 1783-9.

30. Bagel, O.; Limoges, B.; Schöllhorn, B.; Degrand, C. Anal. Chem., 1997, 69, $4688-94$.

31. Hu, L.; Han, S.; Liu, Z.; Parveen, S.; Yuan, Y.; Xu, G. Electrochem. Commun., 2011, 13, $1536-8$.

32. Challier, L.; Mavré, F.; Moreau, J.; Fave, C.; Schöllhorn, B.; Marchal, D.; Peyrin, E.; Noël, V.; Limoges, B. Anal. Chem., 2012, 84, 5415-20.

33. Dequaire, M.; Limoges, B.; Moiroux, J.; Savéant, J-M. J. Am. Chem. Soc., 2002, 124, $240-53$.

34. Limoges, B.; Savéant, J-M.; Yazidi, D. J Am Chem Soc., 2003, 125, 9192-203.

35. Kober, E. M.; Caspar, J. V.; Sullivan, B. P.; Meyer, T. J. Inorg. Chem., 1988, 27, 4587-98.

36. Vianini, E.; Palumbo, M.; Gatto, B. Bioorg. Med. Chem., 2001, 9, 2543-8.

37. Mendes, P. Trends Biochem. Sci., 1997, 22, 361-3.

38. Rudolph, M. J. Electroanal. Chem., 2003, 543, 23-39.

39. In return, the underlying screen-printed carbon electrode was disconnected, while the screen-printed reference and counter electrodes were kept in place to complete the three-electrode assembly.

40. Alexiadis, A.; Cornell, A.; Dudukovic, M.P. J. Electroanal. Chem., 2012, 669, 55-66.

41. Mandin, Ph.; Pauporté, Th.; Fanouillière, Ph.; Lincot, D. J. Electroanal. Chem., 2004, 565, 159-173.

42. Limoges, B.; Marchal, D.; Mavré, F.; Savéant, J-M. J. Am. Chem. Soc., 2006, 128, 2084-92.

43. Bourdillon, C.; Demaille, C.; Moiroux, J. ; Savéant, J-M. J. Am. Chem. Soc., 1993, 115, 2-10.

44. Bond, A. M.; McLennan. E. A.; Stojanovic, R. S.; Thomas, F. G. Anal. Chem., 1987, 59, $2853-60$.

45. Zeis, R.; Lei, T.; Sieradzki, K.; Snyder, J.; Erlebacher, J. J. Catal., 2008 253, 132-8.

46. Miller, E. W.; Albers, A. E.; Pralle, A.; Isacoff, E. Y.; Chang, C. J. J. Am. Chem. Soc., 2005, 127, $16652-9$.

47. Dickinson, B. C.; Tang, Y.; Chang, Z.; Chang, C. J. Chem. Biol., 2011, 18, 943-8. 
48. Leed, M. G. D.; Wolkow, N.; Pham, D. M.; Daniel, C. L.; Dunaief, J. L.; Franz, K. J. J. Inorg. Biochem., 2011, 105, 1161-72.

49. Kuivila, H. G. J. Am. Chem. Soc., 1954, 76, 870-4.

50. Sikora, A.; Zielonka, J.; Lopez, M.; Joseph, J.; Kalyanaraman, B. Free Radic. Biol. Med., 2009, 47, 1401-7.

51. T. Deféver, M. Druet, M. Rochelet-Dequaire, M. Joannes, C. Grossiord, B. Limoges, D. J. Am. Chem. Soc., 2009, 131, $11433-41$.

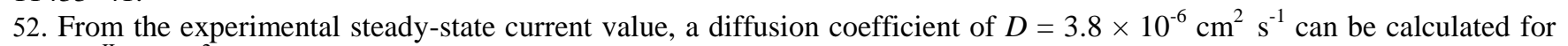
the $\left[\mathrm{Os}{ }^{\mathrm{II}}(\mathrm{bpy})_{3}\right]^{2+}$ using eq 2.

53. Savéant, J.-M.; Su, K. B. J. Electroanal. Chem., 1984, 171, 341-9.

54. In Figure 6, the 3-fold increase in current with L-Tym compared to the initial steady-state current of the one-electron redox mediator alone suggests, under our total catalysis conditions, a catalytic oxidation mechanism of L-Tym based on more than one electron.

55. On the basis of the significantly lower diffusion rate of L-Tym/D-Apt 49 to the electrode, the electrochemical consumption of L-Tym bound to the aptamer was not considered for simulation.

56. Lin, P. H.; Yen, S. L.; Lin, M. S.; Chang, Y.; Louis, S. R.; Higuchi, A.; Chen, W. Y. J. Phys. Chem. B, 2008, 112, 666573.

57. Ruta, J.; Perrier, S.; Ravelet, C.; Fize, J.; Peyrin, E. Anal. Chem., 2009, 81, 7468-73.

58. Bao, J.; Krylova, S. M.; Reinstein, O.; Johnson, P. E.; Krylov, S. N. Anal. Chem., 2011, 83, 8387-90.

59. Wickiser, J. K.; Winkler, W. C.; Breaker, R. R.; Crothers, D. M., Mol. Cell, 2005, 18, 49-60.

60. Gilbert, S. D.; Stoddard, C. D.; Wise, S. J.; Batey, R. T. J. Mol. Biol., 2006, 359, 754-68.

61. Jucker, F. M.; Phillips, R. M.; McCallum, S. A.; Pardi, A. Biochemistry, 2003, 42, 2560-7.

62. Dunford, H. B. Heme Peroxidases, Wiley, New York 1999.

63. Wang, W.; Noël, S.; Desmadril, M.; Guéguen, J.; Michon, T. Biochem. J., 1999, 340, 329-36.

64. Rodriguez-Lopez, J. N.; Gilabert, M. A.; Tudela, J.; Thorneley, R. N. F.; Garcia-Canovas, F. Biochemistry, 2000, 39, 13201-9.

65. Adediran, S. A.; Lambeir, A-M. Eur. J. Biochem., 1989, 186, 571-6.

66. Noble, R. W.; Gibson, Q. H. J. Biol. Chem., 1970, 245, 2409-13.

67. Nakajima, R.; Yamazaki, I. J. Biol. Chem., 1987, 262, 2576-81.

68. Rodriguez-Lopez, J. N.; Smith, A. T.; Thorneley, R. N. F. J. Biol. Chem., 1997, 272: 389-95.

69. Yokota, K.-n.; Yamazaki, I. Biochem. Biophys. Res. Commun., 1965, 18, 48-53.

70. Tamura, M.; Yamazaki, I. J. Biochem., 1972, 71, 311-9.

71. Savéant, J-M., Elements of Molecular and Biomolecular Electrochemistry, Ed. Wiley-Interscience, 2006.

72. Carroll, S.; Marei, M. M.; Roussel, T. J.; Keynton, R. S.; Baldwin, R. P. Sens. Actuators B, 2011, $160,318-26$.

73. Sbartai, A.; Namour, P.; Errachid, A.; Krejci, J.; Sejnohova, R.; Renaud, L.; Hamlaoui, M. L.; Loir, A-S.; Garrelie, F.; Donnet, C.; Soder, H.; Audouard, E.; Granier, J.; Jaffrezic-Renault, N. Anal. Chem., 2012, 84, 4805-11. 